\title{
A Decade of Tomato Transcriptomics: Status and Perspectives
}

\author{
Kinjal Kulshrestha* and Akarsh Parihar \\ Centre of Excellence in Biotechnology, Department of Agricultural Biotechnology, \\ Anand Agricultural University, Anand-388110, Gujarat, India \\ *Corresponding author
}

\section{A B S T R A C T}

Tomato is widely consumed vegetable in the world. It is used as raw and processed form. Tomato flowers are self as well as controlled pollinated. The crop has more than thirteen species including cultivated and wild types with huge diversity and is susceptible to diverse stress conditions. Recent advances in the biotic and abiotic stress in tomato

\section{Keywords}

Solanum

lycopersicum, transcriptomics, tomato genome, RNA Seq., bioinformatics

\section{Article Info}

\section{Accepted:}

15 February 2020

Available Online:

10 March 2020 transcriptomics have been reviewed here. Transcriptome is a particular set of RNA expressed during a stress, developmental stages or a condition in a group of cells. Transcriptomics is a promising technology for understanding molecular interactions during disease, interpretation of functional elements and molecular constituents of cell. Transcriptomics allows indexing all transcripted species such as mRNA \& small RNA; to determine gene structure: start site, 5'and 3'ends, transcriptional modification, splicing patterns; and to quantify differential gene expression in stress condition. There are many techniques of transcriptomics such as RNA sequencing, Microarray, EST and SAGE. Transcriptomics by RNASeq is frequently used system as being cost effective. Sample preparation is a critical step for sequencing procedure. High quality RNA is essential. As transcriptomics yield huge amount of datasets, bioinformatics tools are required for proper data analysis. Gene ontology is obtained as molecular function, cellular components and biological processes. Panel of genes such as WRKY and phenyl propanoid were found to be expressing during stresses in tomato. Evaluation of differentially expressed genes paves the way for candidate gene selection. These genes may be focussed in constructive breeding programs. Researchers recommend the reference tomato genome enrichment and bioinformatics workforce surge.

\section{Introduction}

Tomato (Solanum lycopersicum) is one of the most indispensable vegetable which is cultivated and consumed throughout the world. Tomato is preferred raw as salad and in the processed form such as ketchup, paste, soup, puree etc. by all the age groups. Tomato is a self-pollinated crop in which controlled cross pollination is easily implemented. It belongs to the family Solanaceae, bears $2 n=2 x=24$ chromosome number and berry type fruit (Anonymous, 2014, Table 1). A substantial amount of synteny is observed between the genomes of cultivated and wild tomato species (Chetelat and $\mathrm{Ji}, 2007$ ). Tomato includes more than thirteen interfertile species some of which may interbreed 
(Table. 2). After compound selection events, the present form of tomato has been evolved (Simmonds, 1976).Tomato is a fruit originated in the Andes region, South America (Fig. 1, Simmonds, 1976).

This region includes Peru, Bolivia, Ecuador and Chile these days. The first tomato cultivar to be domesticated is $S$. lycopersicum var. cerasiforme (Fig. 2). Multiple disease resistance sources are packed in wild species like $S$. pimpinellifolium, $S$. peruvianum, S.hirsutum and S. habrochaitis (Rick, 1990). S. penillii, S. chilense and S. peruvianumare the sources for abiotic stress tolerance.

Tomato ranks second, world-wide,in terms of consumption. China, India, USA, Turkey, Iran and Italy are the leading tomato producers in the world. In India, Himachal Pradesh, Uttar Pradesh, Andra Pradesh, Maharashtra, Madhya Pradesh, Gujarat, Telangana, and Karnataka are the leading tomato producing states in India (Table 2).

The area, production and productivity of tomato is 5.02 Mha, 170.75 MMT and 33.99 $\mathrm{MT} / \mathrm{ha}$ for the world whereas0.80Mha, 19.96 MMT and $24.34 \mathrm{MT} / \mathrm{ha}$ for India (Anonymous, 2018, Table 3). Tomato juice and pulp are mild aperients and blood purifiers. Tomato is a rich source of vitamin A, C, E and lycopene. Tomato plants are found with determinant type as well as indeterminate type growth habit. Tomato flower is a cymose type inflorescence.

The flower petals shed away upon fertilization. Pea shaped fruit starts developing which ultimately gains size and become red. The breeding objectives in tomato are as follows:

a) Abiotic stress tolerance

b) Biotic stress resistance

c) Quality improvement

d) Earliness
Abiotic stress includes drought and salt tolerance etc. Biotic stress includes different disease and insect-pest whereas fruit quality improvement includesfruit firmness, early maturity, lycopene content, total soluble sugar content and total soluble solids etc.

Major diseases in tomato are Early blight, Late blight, Fusarium wilt, Bacterial wilt, Damping off, Tomato Leaf Curl virus, Tomato Yellow leaf curl virus, Tomato Mosaic virus, Bacterial Spot, Bacterial Canker, Tomato Bunch Top Virus, Tomato Spotted Wilt Virus and Powdery Mildew (Anonymous, 2014).

The continuous selection process of cultivated species and its domestication has made tomato species susceptible to many stresses. Introgression from the wild species is recognized (Sahuand Chattopadhyay, 2017). Transcriptomics is a boon to spot the resistant gene for the gene transfer in the cultivated lines from the wild type plants and resistant germplasm for crop improvement.

\section{Transcriptomics for crop improvement}

Transcriptomics is the study of transcriptome which is a complete set of RNA transcripts that are produced by the genome, under specific circumstances or in a specific cell. Gene expression pattern reflects the molecular mechanism which governs the final biology and physiology of plant.

In this way, transcriptome is critical to be understood as it reveals the complex disease traits. Though we have many methods for studying the transcription processes like RNA Microarray, ESTs, SAGE etc. but RNA sequencing has emerged as the most exploited technology among all of them (Lowe et al., 2017). RNA Seq is a unique technology as it has whole-transcriptome coverage. Traditional methods such as qPCR and 
microarray have limited range, less sensitivity and above all, they rely on prior information of the genome. On the other hand, RNA Seq. offers studying novel transcripts as well as synteny. RNA Seq shows insights of functional pathways based on the particular gene expression during critical conditions. It delivers high sensitivity and accuracy along with lower cost per sample. The final number of sequences analyzed depends on the objective of the research work.

High throughput sequencing technology enables the researchers to locate the gene function quantitatively. Sequencing run allows us to zoom in a particular region of the genome. The disease resistance may be governed by single genes or group of genes. Transcriptomics is the platform to identify the candidate gene or genes which are up regulated or down regulated during certain stress. These genes can be studied for additional information and can be introgressed in the susceptible genotype through conventional or modern methods after complete evidence.

In Microarray, the diseased samples are hybridized with the probes on a chip and differential gene expression is studied (Table 4). Microarray is parallelism, miniaturization, automation and multiplexing process. There are two stages to design the chip namely by probe hybridization and measuring the gene expression of controlled and diseased samples. RNA Seq is used for studying GO (Gene Ontology), KEGG (Kyoto Encyclopedia of Genes and Genomes) and differential gene expression (Bolger et al., 2017). Comparison of transcriptome allows the identification of genes that are differentially expressed in distinct cell populations or in response to different treatments or during diseases. To carry out transcriptomics, extreme genotypes like resistant and susceptible, sufficient selection pressure, adequate infrastructure, appropriate software, platforms and databases are required.

\section{Advantages of RNA Seq}

1) De novo sequencing.

2) Qualitative as well as quantitative transcriptome analysis.

3) High sensitivity and accuracy.

4) Low cost in comparison to arrays.

5) Multiple conclusions can be drawn using correct bioinformatics tools.

6) Unaffected by the background noise and saturation of the signals.

7) Captures subtle gene expression.

8) Quantifies the digitally discrete read counts.

9) Highest numbers of DEGs may be netted.

\section{Applications of transcriptomics in crop improvement}

Facilitating a breeder by gene identification for disease resistant traits.

To explore the distinctive gene in wild species.

Searching the candidate genes for resistance and explore its biosynthesis.

Identification of the genetic basis of disease and resistance.

Annotation of the function of previously unannotated genes.

Identification of single nucleotide polymorphism (SNPs).

To carry out gene expression studies for nonmodel crops.

Identification of previously unknown protein coding regions in existing genome database.

To enrich the public data bases with the annotated sequences.

To get information about putative proteins. 
Check points as challenges and way to combat them

\section{RNA degradation}

RNA being sensitive to RNase, utmost care should be taken while crushing the sample, dissolving the pellet and handling the aliquotes of RNA because RNase present on the working platform, instruments or old gloves will affect the final RNA quantity. Autoclaving of mortar-pestle, chloroform treatment of tips, pipettes and DEPC (Diethyl pyrocarbonate) water is recommended during the whole procedure.

\section{Presence of genomic DNA in the sample}

The presence of genomic DNA should be minimized by treating the sample with DNase and selection of proper RNA extraction method. DNA contamination may give high nucleic acid content during quantification but lower amount of actual RNA bind to adaptors. When the sample is loaded in agarose gel wells, DNA contamination gives a clear bright and heavy band while RNA appears in a smear form.

\section{Quality check}

Nucleic acids have absorbance of $260 \mathrm{~nm}$ but EDTA, phenols and carbohydrates absorb wavelength of $230 \mathrm{~nm}$. The RNA with $260 / 230$ ratio of 2 , near 2 or above is advisable for transcriptomics studies. If it is lower than 2, it indicates presence of phenols. Lower 260/280 ratio (less than 2) indicates the presence of protein in the sample. The pure nucleic acid has higher 260/230 ratio when compared with $260 / 280$. The ratio gives an idea about protein or DNA contamination.

\section{Techniques under transcriptomics}

The extracted RNA is subjected to cDNA fragments with adapters either on one side or both the sides. Then each molecule is sequenced by single end sequencing or paired end sequencing.The read length varies between 30-400 bp based upon the technology used. The proper technique should be selected based on the aim of the study. Samples under a gradient of stress can be compared by this technique. Novel transcripts are also mapped in RNA Seq while microarray requires predefined probes for the DNA fragment hybridization. RNA Seq reveals precise location of transcription factors and sequence variation. RNA Seq has very low background noise. Splicing diversity is also explored by RNA Seq during splice junction analysis.

\section{Validation}

Validation gives the strength to the research as it validates the gene expression in the samples. Validation is done by reverse transcription polymerase chain reaction (RTPCR). Real-time PCR technology records the amplification in real time. Real-time PCR reveals the expression in terms of absolute and real quantification. Absolute quantification concludes the input copy number by using standard curve. Relative quantification of target genes is done by comparing the expression with a reference gene or control group.

\section{Tomato genome}

The tomato genome was published in Nature on $31^{\text {st }}$ May, 2012. Its genome size is $950 \mathrm{MB}$. The Tomato Genome Consortium 2012, consists of over a hundred of researchers from 14 countries. IARI, New Delhi also contributed in the research. Initially, the gene rich regions of 12 chromosomes were sequenced using BAC-by-BAC sequencing approach. In 2008, the whole genome sequencing approach was implemented. Inbred tomato cultivar 'Heinz 1706' from Pittsburgh, PA, USA was used for sequencing 
using Sanger and 'next generation' technologies. In 2008, Shotgun sequencing was performed using Sanger sequencing method. The predicted genome size was 900 $\mathrm{Mb}$ from which $760 \mathrm{Mb}$ assembled into 91 scaffolds aligning to 12 tomato chromosomes. Base accuracy of one substitution error per 29.4 kilobases and one indel error per $6.4 \mathrm{~kb}$ was retained.

Genome of S. pimpinellifolium LA1589 was assembled de novo which yielded $739 \mathrm{Mb}$ of data sets. Divergence between wild and domesticated tomato genomes was $0.6 \%$ hence, 5.4 million single nucleotide polymorphisms (SNPs) were distributed along the genome. Tomato chromosome has pericentichetrochromatin and distal euchromatin region. The genome was found to be highly syntenic with other Solanaceae members such as potato, eggplant, pepper and nicotiana. Comparative genomics study has reported 34,727 and 35,004 protein coding genes in tomato and potato respectively.

From the above genes 31,741 and 32,056 genes respectively show synteny to Arabidopsis genes. All the protein coding genes of tomato, potato, Arabidopsis, rice and grape were clustered in 23,208 gene groups and 8,615 gene groups were common to all. Eudicot genomes (tomato, potato, grape and Arabidopsis) has 1,727 gene groups while 727 was common in fleshy fruits (tomato, potato and grape). Small RNA sequencing predicted 96 and 120 conserved miRNA genes in tomato and potato respectively.

Total 34 miRNA families were identified among which 10 are highly conserved in plant kingdom. Tomato-potato orthologous regions approve nine large inversions based on cytological or genetic studies. Total 18,320 orthologous tomato-potato gene pairs were identified accurately. Alignment of $71 \mathrm{MB}$ of euchromatic tomato genome revealed $8.7 \%$ of nucleotide divergence from potato genome whereas heterochromatic sequences showed $30 \%$ of nucleotide divergence.

Comparative mapping of 31,760 'Heinz 1706' genes and $S$. pimpinellifolium revealed 7,378 identical genes, 11,753 synonymous changes and 12,629 non-synonymous changes. 'Heinz 1706' carried introgression from $S$. pimpinellifolium detectable on chromosomes 4, 9, 11 and 12.

Comparative transcriptome of tomato and grape supports the hypothesis that a wholegenome triplication affected the rosid lineage in common eudicot ancestor (The Tomato Genome Consortium, 2012).

NGS platforms used were Roche/454, SOLiD and Illumina sequencing which provided 21 GB, $64 \mathrm{~GB}$ and $82 \mathrm{~GB}$ data respectively. Newbler and CABOG programs were used to generate the independent assemblies (Sato and Tabata, 2016).

\section{Recent advances of transcriptomics in tomato}

Recent advances of transcriptomics in tomato found to be distributed as the following areas of work

Comparative transcriptome analysis of cultivated and wild species of tomato

Comparative transcriptome analysis of tomato cultivars

Transcriptomic analysis during abiotic stresses in tomato (drought \& salt tolerance)

Transcriptomics during biotic stresses in tomato (nematode, TYLCV, fungi and early blight)

Transcriptomic analysis of pollen developmental stages of tomato

Transcriptomic analysis of hormone effect on tomato 
Comparative transcriptome analysis of cultivated and wild species of tomato

The section Lycopesicon includes about13 tomato species. The cultivated tomato is $S$. lycopersicum whereas $S$. pennellii, S. pimpinellifolium, S. cheesmaniae, S. galpagense, S. chemelewskii, S. arcanum, $S$. neorickii and $S$. huaylasense are wild tomato species. Domestication is affected by continuous selection along with human migration. Suitable wild accessions are selected according to phenotype, adaptability and nutritional value. Better yielding loci are selected recurrently. Positive selection of some loci leads to lack of diversity. Domestication of tomato was oriented towards increase in yield and fruit size. These selection events can be studied during comparative high throughput sequencing. The present cultivated tomato was domesticated from $S$. pimpinellifolium. First domesticated cultivar is represented by $S$. lycopersicum var. cerasiforme. Tomato was re-introduces in America by Europeans about 300 years ago. Wild tomato varieties have wide genetic phenotypic base but the cultivated tomato is with selected genes. Transcriptome analysis of cultivated and wild tomato species seems to be informative for understanding the difference at molecular levels. Wild tomato species are sources of resistance for certain diseases. During resistance, the pattern of transcription factor plays an important role.

SRA sequences (Koenig et al., 2013) of $S$. lycopersicum and $S$. pennellii were taken as cultivated and wild species respectively, which offered different gene expression due to natural and artificial selection. Seven different tissue types were studied namely root, stem, leaf, flowers, fruits, seedlings and vegetative portions. Total 62,676 transcripts were generated. The quality of RNA-Seq data was studied by FastQC software. Alignment of RNA Seq data was done by Tophat and transcripts were assembled by Cufflinks. Cuffmerge was used for merging the assemblies. Differentially expressed genes, transcripts and differential splicing were recognized by cuffdiffat False discovery rate FDR $<0.05$ with Python script. Long noncoding RNA was selected on the basis of size (length $\geq 200 \mathrm{bp}$ ), ORF filter was $\leq 100$ and the coding potential calculator (CPC) prediction was used for non-coding sequence detection. Gene ontology was done by AgriGO was used for gene ontology. Gene ontology was enriched by Hypermetric extract test at FDR $<0.05$ (threshold). Pathway analysis was done by KOBASS. Total genes expressed in cultivated tomato were 18,719 and in wild were 18,609 . Most of the genes were found to be co-expressed in both (17,202 genes). Genes expressed only in cultivated type were, 1,517 and in wild were 1,407. Differential genes were found to be expressed in floral, fruit, vegetative and root tissues. Total 618 genes were expressed in roots. Root samples had gene ontology (GO) for cellular composition (CC) and molecular function (MF). Fruits had GO for biological processes (BP). The pathways obtained were for heat and salt stress tolerance. The differences in gene expression were found mostly in carbon metabolism, sucrose metabolism, amino acid biosynthesis and gluconeogenesis. Differentially expressed long non coding RNA were 554 however coding were 426 (Dia et al., 2017).

Genome-wide sequence variation between wild and cultivated tomato species by whole genome sequence mapping has been studied (Kumar and Chattopadhyay, 2017).Tomato sequences were taken from The Europian Bioinformatics Institute (EBI) database. These sequences were submitted by Aflitos et al., (2014). SNPs were detected and the effects of them were analyzed by SnpEff. The bcf files of whole data were converted to vcf file by samtools, then from vef to hapmap. 
Hapmap diversity was analyzed by Tassel, Pi, Theta, Fst and Tajima's D values. gff annotation file plotted the stress resistant genes. SNP and InDel mining was analyzed for 29 accessions of 12 wild and 40 accessions of $S$. lycopersicum. All the wild species have unique set of SNP which was absent in the cultivated types. Low sequence variation was observed among red fruited species like $S$. pimpinellifolium, $S$. cheesmaniae and $S$. galpagenses when compared to cultivated tomato sequences. The green fruited species like $S$. chemelewskii, $S$. arcanum, S. neorickiiand $S$. huaylasense, showed much variation when compared to $S$. lycopersicum sequences. Common SNPs were least in $S$. pennellii and lower in $S$. arcanum, $S$. huaylasense and $S$. habrochaites. The strategy concluded that, there is a wide genetic variation among the wild accessions. $S$. peruvianum and S. chilense had $50 \%$ variation: lower SNPs. S. arcanum had highly divergent accessions. The ratio of genic SNPs to total SNPs, increased with increase in phylogenetic distance. S. pimpinellifolium have highly dense SNPs in the chromosome 1, 3, 4 and 8. Chromosomes 5 and 7 had the lowest SNP numbers within the same species. $S$. cheesmaniae and $S$. galpagenseare very similar but entirely different from $S$. pimpinellifolium. $S$. cheesmaniaeand $S$. galpagenseare known as morphotypes originated on the Galpagos Islands. $S$. pimpinellifolium was originated in Andese. Arcanum subsection species, S. chmielewskii, $S$. neorickiiand $S$. arcanum appear to be similar on the basis of SNP. The first two are closer and are originated on Andese mountain ranges. The third species was originated on Andean coast.

The genetic variation by sequencing 84 tomato accessions and related wild species was discovered (Aflitos et al., 2014). Groups involved in the study were Lycopersicon, Arcanum, Eriopersicon and Neolycopersicon.
The full genetic diversity of tomato crop was explored. DNA was isolated by standard DNA isolation protocol (Van der Beek et al., 1992). Qubit 2.0 was used for DNA quantification. DNA sequencing was done by IlluminaHiSeq 2000 for mapping of $S$. lycopersicum cv. Heinz v 2.40. The maximum insert size was $750 \mathrm{bp}$.Samtools was used for variant calling with minimum gap distance of $5 \mathrm{bp}$, minimum alignment quality of 20 and minimum depth equal to 4 . Bowtie was used to check the contamination of Escherichia coli, human, insect, mouse, bacteriophage, yeast and phytoviral genomes. De novo sequencing of $S$. arcanum(LA2157),S. habrochaites(LYC4) andS. pennellii(LA0716) was done by using Illumia HiSeq2000. All the data for $S$. pennellii, $S$. habrochaites, $S$. arcanum and $S$. lycopersicum was assembled using AllPaths-LG. S. arcanum was also assembled by CLC workbench $\mathrm{v} 7$ with bubble size 300 , minimum contig length 200 and a word size of 64 . The scaffolds obtained by AllPaths-LG were further scaffolded using 454FLX data, Scarpascaffolder. Resultant de novo assembly statistics were compared with tomato reference genome, S. lycopersicum cv. Heinz version SL 2.40. S. arcanumverson 1.0, S. habrochaites version 2.0 and S. pennellii version 2.0 were used for mapping of 84 accessions. The sequence diversity was assessed by BLASTN hits of CLC assembled contigs and ITGA $\mathrm{v} \quad 2.4$ annotation. Sequences were aligned by Clustal W. SNP calling was done by quality based variant detection algorithm of CLC. BWA and samtoolswere used to generate vcf files. All vcf files were processed by SNPEFF 3.4 and ITGA annotation was done. Parameters such as synonymous and non-synonymous SNPs, heterozygosity levels, the number of SNPs per $1 \mathrm{Mbp}$ bins and location of SNP were assessed. JBrowser 1.10.12 was employed to detect the structural variants. The assembly of SL2.40 and ITGA 2.32 genome annotation was laden with the vef files of 84 accessions. 
The sequences were deposited at European Nucleotide Archive with the accession numbers PRJEB5226 (S. arcanum LA2157), PRJEB5227 (S. habrochaitesLYC4), PREB5228 (S. pennellii) and PRJEB5235. The whole genome sequencing coverage was found 36 fold and SNPs in wild species were more than 10 million. Allogamous selfincompatible wild species showed the highest heterozygosity. The habitat and the origin of species influenced the phylogenetic relationships. The mapped reads for $S$. habrochaites, S. arcanum and S. pennellii, were $78 \%, 73 \%$ and $53 \%$ respectively. This showed the presence of interspecies variation. Reconstruction of additional reference genomes for tomato was recommended. There was $1 \%$ each of synonymous and nonsynonymous SNPs. A segment of $2.2 \mathrm{Mb}$ on chromosome 6 was found to be introgressed in S. lycopersicum lines namely LA2838A, LA2706 and CGN15820 andS. pimpinellifolium (LYC2798) was found to be the closest donor for that.

RNA sequencing for identification of changes in the DNA sequences and gene expressions in cultivated and wild species of tomato was performed (Koenig et al., 2013). RNA sample of S.lycopersicum, S. pennellii, $S$. habrochaites, S. pimpinellifolium, $S$. chmielewskii and $S$. galpagense were used. All the species selected were diverse in their habitat as well as the genetic content. RNA was extracted using Trizol and RNeasy kit. Sequencing was done by Illumina GA II and HiSeq 2000, SNP detection, indels between samples and reference were studied by Biopearl script.

Statistical analysis was done by R-statistical programming environment. The samples aligned upto $67.4 \%$ to the reference genome. The reads covered 54\% of annotated genes and 34 novel transcripts were found which differed from the published S. lycopersicum genome. Cultivated accessions had <1 SNP/ $\mathrm{kb}$. Total 51 genes showed statistical significance $(\mathrm{P}<0.05)$ for evolution through positive selection. In the centromeres, there was low amount of gene expression when compared to the whole chromosome. This chromosomal part had high gene density. $S$. pennellii had the highest expression variability among all the species. $S$. lycopersicum showed divergence in the expression.

It was concluded that redox pathway had been evolved as it was having much higher expression in the wild species i.e., $S$. pennellii, $S$. habrochaite and $S$. pimpinellifolium. The pathway may be useful for these species as they belong to tough environmental conditions. S. pennellii governed many genes which are responsible for abscisic acid pathway, salt, drought, oxidative damage and heat stress etc. $S$. pennellii lineage displayed the highest proportion of expression changes. This proved that $S$. pennelli is highly diverse when compared to all other species in the study. Connective genes were identified among $S$. pennelli and S. lycopersicum in the form of modules. Few genes were highly connected to $S$. pennelli, though they were present in both the species. The genes for photosynthetic tissue specific expression were correlating $S$. pennelli and S. lycopersicum.

\section{Comparative transcriptome analysis of tomato cultivars}

The cultivars are selected on the basis of desired characteristics and are maintained carefully for breeding and selection. The common names of the cultivars are usually inspired by region or the developers. Due to difference in the origin, worldwide, tomato cultivars have few genetic differences. AT3, SL120, Hissar Lalit, Arka Vishal, Rajshree, Rupalietc are popular tomato cultivars in Indian. 
Mnichal (S. lycopersicum) as normal $(\mathrm{N})$ and stunted (S) cherry tomato plants was sequenced (Rahim et al., 2018). RNA was extracted by RNeasy mini kit. TrueSeq RNA library preparation kit (Illumina) was used for library preparation. IlluminaHiSeq 2000 was used as a genome sequencer. The transcripts were mapped to Ensemble database with TopHat v.2.1.1. Assembely was examined by Swiss Prot database and for gene ontology. Cufflink gave the expression pattern. DEGs were found by DESeq at $\mathrm{p}=0.005$ and $\mathrm{q}=0.05$. GO and KEGG were done by WebGestalt and DAVID. qRTPCR was done by LightCycler 96, Roche Life Science, Germany and the data was analyzed by LightCycler 96 software. There were total 117.99 Million paired reads. Clean reads were 115.45 Million. Mapping of Mnichal $(\mathrm{N})$ matched $97.6 \%$ and of cherry tomato (S), $98.0 \%$ with S. lycopersicum genome. There were 35,216 transcripts and 35,216 genes in $\mathrm{N}$ and $\mathrm{S}$ respectively. Seventy two percentage of the sequence of $\mathrm{N}$ had $90-100 \%$ coverage, while for $\mathrm{S}$, it was $71 \%$. At Q20, $96.60 \%$ sequences were represented for $\mathrm{N}$ and $96.81 \%$ for $\mathrm{S}$. Total DEGs in N and S were 661 and total 420 genes were up-regulated whereas 214 were down-regulated, 32 genes expressed only in S and 108 only in $\mathrm{N}$.

The gene ontology showed genes for metabolic process, response to stimulus and biological regulation under biological processes (BP), whereas for membrane and nucleus under cellular components (CC), and protein binding, ion binding, nucleic acid binding and hydrolyase activity under molecular function (MF). The enriched GO terms gave the genes for catalytic activity and metabolic process. The functional annotation clustering showed 22 clusters with score in the range of 0.02 to 2.37 . Among them, six clusters recorded enrichment score greater than 1.0. Highest enriched terms were for steroid biosystem, WRKY transcription factor, DNA damage/repair, tetratricopeptide repeat, MADS-box TF and mitogen activated protein kinase. Transcripts for RPA3B, RPA2B, XRCC3 and RPA1E are related to homologous recombination; Adenylateisopentyl transferase-3, related to cytokinin biosynthesis and cytokinin oxidase 3 (CKX3) catalyzing the degradation of cytokinine, were up-regulated in S, cherry tomato. Genes 3BETAHSD/D2, DWF5 and DIM are related to steroid biosynthesis and were down-regulated in S. Genes of auxin signaling pathway namely IAAI4, AX6B_SOYBN, AXX15_SOYBN and $12 K D \_F R A A N$ were found to be up-regulated however AIR12 was down-regulated in stunted tomato plants. Ethylene biosynthetic genes viz. 1-aminocyclopropane-1carboxylate oxidase 1 (ACO1) and 1 aminocyclopropane-1-carboxylate oxidase 3 (AOC3) have a higher expression in S.ERF (ethylene responsive genes), specifically ERF13 was down-regulated in S. ERF003 and ERF13 exhibited nil expression in N. WRKY TF genes viz. WRKY 40, WRKY41, WRKY50 and WRKY51 found to be up-regulated in $\mathrm{S}$. MADS box TF genes including AGL36 and SEPALLATA 2 were up-regulated while SVP and AGL19 were down-regulated in S. YDA (MAPK) (cell expansion) was down-regulated in $\mathrm{S}$ and the TRP like genes, namely FKBP65, LPA1 and NOXY38 were down-regulated while ATSDII was up-regulated in S.

The transcriptome of tomato (S. lycopersicum) cultivars Ailsa Craig (AC) and HG-6-61 was evaluated at seven stages viz. 7DAF (Days After Flowering), 14DAF, 21DAF, 28DAF, 35DAF, 42DAF and 49DAF by Ye et al., (2015). The RNA was extracted by Green spin RNA quick extraction. Sequencing was done by Illumina AnalyzerIIx. The clean reads were mapped to SL2.40 version of tomato genome from SOL Genomics, using Tophat (v 2.0.4). Differential expression was analyzed by 
EdgeR and the GO enrichment was done by DAVID (Database for Annotation, Visualization and Integrated Discovery). Primers for qRT-PCR were designed by Primer 3. The ascorbic acid, carotenoid and flavonoid content were estimated using HPLC. Sequences of Heinz and $S$. pimpinellifolium were downloaded from TFGD (Tomato Functional Genomic Database). Co-expression analysis was done by CORREL, Excel 2003. cDNAs of transcription factors of MYB, NAC and ZIF were amplified. Lycopene (carotenoid) and naringeninchalcone (flavonoid) were found to be higher in AC earlier to HG-6-61. Ascorbic acid was higher in HG-6-61 at 49 DAF when compared to AC. Though, carotenoid content was increasing with maturity in both the samples but rate of accumulation was faster in AC. All the flavonoids increased with maturity except chlorogenic acid and rutin. The RNASeq yielded $9.5 \mathrm{M}$ reads per sample. For AC, $95.88 \%$ and for HG6-61, 96.03\% of the sequences were uniquely mapped to $S$. lycopersicum. Average CDS for AC was $77.31 \%$ although for HG6-61 it was $76.65 \%$. Total 26,392 genes were found to be expressed, which is $76 \%$ of 34,727 genes in the reference genome. This showed a saturated coverage of expression. Total 14,758 genes were expressed in all the stages and five of these were most expressed in AC at all the stages with RKPM $>4000$. Two of these genes, Solyc05g0530702 and Solyc05g0540902 are located on the chromosome number 5 and encode a protein with unknown function. Solyc01g110700.2 is located on chromosome number 1 and codes for pre-mRNA splicing factor ATP dependent RNA helicase. Solyc01g109660.2 is also located on chromosome 1 and codes for CCR 2 glycine-rich RNA binding protein. Solyc11g008510.1 codes for 60s ribosomal protein. K- mean cluster analysis of 26,397 genes' expression pattern gave 20 groups. The largest group was of 3,523 genes $(13.2 \%)$ which had a stable expression at 14DAF, 28DAF, 35DAF, 42DAF and 48DAF. This group has genes for cell wall, protein modulation and RNA regulation. The second largest group had 2,763 genes (10.5\%), stable at all the stages and codes for protein and development categories. The third largest group had 2,130 genes (8.1\%), with declining activity from 7DAF to 42DAF but activity level arose at 49DAF. AC had 3,531, 5,576, $7616,8,645,8,968$ and 9,878 differentially expressed genes at 14DAF, 21DAF, 28DAF, 35DAF, 42DAF and 49DAF, respectively. There were 20 transcription factors for flavonoid metabolic pathways among them 12 were positively correlated and eight had negative correlation. Total 37 transcription factor were there for carotenoid biosynthesis pathway. MADS box showed high correlation with carotenoid synthesis but the ascorbic acid metabolic pathway had positive correlation with oxidized ascorbate accumulation.

\section{Transcriptomic analysis during abiotic stresses in tomato}

Stress affects the plant's metabolism, growth and root development in numerous ways. Response towards the stress is governed by the interactions at molecular level. Abiotic stress is caused by non-living entities like salt, water logging or drought.

\section{Salt stress}

Various accessions of $S$. pimpinellifolium are reported to possess high salinity tolerance and thus are the reliable source of salt tolerant alleles.Though many QTLs (quantitative trait loci) are also identifies in S. pimpinellifolium for biotic tress (Chen et al., 2013), abiotic stress (Cheng et al., 2010), fruit quality traits (Capel et al., 2015) and other agronomic traits. S. pimpinellifolium has been evolved in challenging environmental conditions and 
carries phenotypic robustness while the cultivated species of tomato has lost those traits during domestication. Salt stress is economically important factor in plant growth. This type of stress is reported to disturb $20 \%$ of irrigated land and reduce the food production by one-third (Machado and Serralheiro, 2017). Ion toxicity, oxidative stress and nutritional disorder are created throughout the salt stress. The water up-take is affected due to high concentration of sodium chloride in cytosol and cell organelles. These all cause unstable production. The combined application of $\mathrm{NaCl}$ and $\mathrm{CaCl}_{2}$ has been reported to increase antioxidant activity in plants. $\mathrm{NaCl}$ is known to delay the tomato seed germination time, seedling length and vigor. Calcium supplement to the seedlings alleviated the effect of salt.

The sequencing of $S$. pimpinellifolium (LA 0480) was done and 15 genes for salt tolerance were elucidated (Razali et al., 2018). S. pimpinellifolium is the closest species to the cultivated tomato i.e., $S$. lycopersicum (Tomato Genome Consortium, 2012). Total 25,134 protein coding genes were annotated. $S$. pimpinellifolium has small red fruits and is facultative autogamous. The species is well distributed in costal Peru, Equador and Chile. So it has genes for salt tolerance due to exposure to the brakish ground water. The sequencing was done by IlluminaHiSeq 2000, with the depth of 197x which gave data of $811 \mathrm{Mb}$ (N50, 75,736 bp). RNA was extracted by ZR Plant RNA mini preparation kit, Zymo. Library was prepared by NEBNext Ultra RNA library preparation kit. Trimmomatic was used for removing adaptor sequences. Trinity v 2.0.6 was the assembler. TransRate (reference free quality assessment tool) removed all the low quality transcripts. BUSCO (Benchmarking Universal Single Copy Orthologs) searched the completeness of the genome assembly and protein annotation was done usingSwissProt. Functional domain, protein signature and associated gene ontology was found using InterProscan. OrthoMCL was employed to read orthologous and paralogaous protein relationships between different species in the study. BWA was the aligner while CIROS was used for circular plot. The SNP calling was done bysamtools. Inositol was measured by K-INOSL assay kit. DEAP was developed and used for annotating protein coding genes. Inositol-3-phosphate synthase and phosphatase genes were significantly higher in number in $S$. pimpinellifolium. So it was concluded that inositol pathway may play a role in salt tolerance of LA 0480. Genes which had orthologs in S. pimpinellifolium and S. lycopersicum are AtCIPK24 (Osmotic signaling stress signaling), AtHKT1 and AtDREB2A (Ion exclusion from shoot), AtSOS, SINHX1, AtNHX3 (Tissue tolerance vacuolar $\mathrm{Na}^{+}$compartmentation); AtVP1.1, PcMIP, tomPRO2 (tissue tolerance increased proton pumping), AtTPS1 (Tissue toleranceSynthesis of compatible solutes), SIAPX, AtAPX1, SIGST, AvSOD and AtMDARI (Tissue tolerance- degradation of reactive oxygen species).

\section{Drought}

Plants are called to be drought stress when the transpirational demand is higher than the root capacity. The reasons of drought are high temperature, windy environment and rapid growth. High humidity also reduces the transpirational water movement. The drought phenotype resembles late blight in tomato. So it is crucial to identify the correct cause of plant health retardation by molecular biology tools. Under drought stress, net photosynthesis, stomatal conductance, intercellular $\mathrm{CO}_{2}$ concentration, gross $\mathrm{O}_{2}$ uptake evolution and gross $\mathrm{O}_{2}$ uptake decline. Tomato plant avoid photodamage by downregulating PSII activity, emitting 
substantial portion of light as heat, declined $\mathrm{CO}_{2}$ assimilation, reduced stomatal conductance and using oxygen as alternative electron acceptor in photorespiration or Mehler reaction.

Tomato samples under drought and rewatered condition were compared by RNA sequencing (Lovieno et al., 2016). The cultivar selected was M82 (LA3475) which was from TGRC, California. RNA was extracted by Trizol method. cDNA libraries with IlluminaTrueseq RNA kit were prepared and sequencing was done by IlluminaHiSeq 1500 platform. Raw reads were trimmed by TrimGalorepackage (www.bioinformatics. babraham.ac.uk). Cutadapt was used to remove the adapters. Quality was checked by FastQC. Mapping was done by Bowtie (v 2.2.0) and TopHat (v 2.0.8). Stomatal conductance, $\mathrm{CO} 2$ assimilation, chlorophyll fluorescence, ABA, proline content and genes for photosystem were measured in the samples. Many DEGs were found to be downregulated during the drought stress. Drought samples namely Dr1 and Dr2 were compared with watered plants (WW and RW).

Total 119 DEGs were common in all of them. Genes for histone, cell modifying enzymes, heat shock proteins and chlorophyll were found in the groups. Gene ontology showed that genes for photosynthetic light harvesting, chlorophyll $\mathrm{a} / \mathrm{b}$ binding and cell wall modification (Pectinases, Solyc09g075350) were down regulated in Dr1 and Dr2 samples. Heat shock proteins were up regulated in Dr1 and Dr2 however Histones and chlorophyll genes were down regulated in Dr1 and Dr2. Pyrroline-5-carboxylate synthase (P5CS) and 9-cis-epoxycaratenoid dioxygenase (NCED)coding genes, Solyc08g043170.2.1 and Solyc07g056570.1 respectively, were validated by qPCR. Sample Dr1 had high expression of P5CS and Dr2 had for NCED.

\section{Transcriptomics during biotic stresses in} tomato

Biotic stress is caused by biological agents. Bacterial, fungal, nematode infections are common obstacles for plant health. After a stress, the stress response is initiated at cellular level which activate signal transduction pathways that transmit information within the individual cell and throughout the plant. This phenomenon leads changes in many gene networks. Biotic stress activated $\mathrm{R}$ proteins and results in hypersensitive response (HR) and plant immunity. There is $\mathrm{H}_{2} \mathrm{O}_{2}$ accumulates at the site of pathogen attack (oxidative burst) induction of programmed cell death (PCD). HR, PCD and systematic acquired resistance (SAR) are characterized by higher expression of several genes which codes for PR proteins. Mitogen-activated protein kinase (MAPK) cascade is present in higher plants which plays an important role in signal transduction in response to hormone, biological signals, pathogen attack and environmental stress (Gorovits and Czosnek, 2007).

\section{Nematode}

Nematodes are obligate endoparacite of plants. They damage the host root system severely. Nematode stress affect the nutrient and water uptake of plants hence plant growth is retarded. Due to gall formation, coarse roots increases. Fine root system is indispensible for healthy plant but root galls reduce the hydraulic conductivity of the root system. Nematode infected plants have lower leaf water potential hence lower stomatal conductivity, transpiration and photosynthesis. The affected cells are the nematode feeding sites known as giant cells. Two oesophageal gland types namely two subventral glands and one dorsal gland are promoting effector production. Plant parasitic nematode has several cuticle proteins which 
are crucial for parasitism. Plant defense system, is suppressed during the nematode infection (Iberkleid et al., 2015).

The differentially expressed genes in susceptible and resistant tomato during nematode infection were identified (Shukla et al., 2018). The nematode susceptible cultivar Pusa Ruby (PR) and Moneymaker (MM) as a nematode resistant samples were taken. Nematode infected root samples were taken at different infection stages. Stage 1: 1, 2, 3 dpi (days post nematode infection), stage 2: 5, 6, 7 dpi; stage 3: 13,14, 15 dpi; stage 4: 18, 19, 20 dpi and stage 5: 26, 27, 28 dpi for Pusa Ruby. Money Maker had only two stages of the above as 1 and 2. The RNA was extracted by Trizol method. HiSeq 2000, Illumina was used as sequencing platform. Demultiplexing of data was done by CASAVA whereas TopHat was used for the alignment while annotation was done by PANTHER database and transcription factors were identified by BLASTX. DEGs were recognized by DESeq2. Gene enrichment was done by AgriGO. Functional categorization was done by using MapMan. The sequencing data had $1,154,560,291$ pair-ended reads for replicate 1 and 537,461,341 single-end reads for replicate 2 of 100bp in length. Genes mapped to $S$. lycopersicum, assembly SL2.50 were 72$92 \%$ in all the samples. Total reads mapped toMeleidogyne incognita were 0.1-6.3\%. The resultant raw data and the processed data were submitted in GEO (Gene Expression Ominbus) repository of NCBI (National Center for Biotechnology Information) with accession number GSE88763 and SRA accession number SRP091567. In PR, 24,411 genes were found to be expressed, out of which, 1,827 were significantly differentially expressed. In stage 2, 18 DEGs; stage 3, 905 DEGs; stage 4, 1,054 DEGs and stage 5, 1,308 DEGs were found. In MM, 23,393 genes were expressed. There was absence of DEGs at stage 1 in MM but stage 2 had 25
DEGs. Genes found to be differentially expressed were for cell wall degradation: (43 genes), cell wall modification (29 genes), cell wall protein ( 5 genes) and cell wall synthesis under differential regulation for altered cell wall architecture. For developmental genes; cell cycle (3 genes), cytoskeletal organization (2 genes), root cap proteins (7 genes), transcription factor controlling developmental processes (5 genes) were found to be differentially expressed. Genes involved in ethylene and jasmonic acid biosynthesis were also found to be differentially expressed. Solyc01g080500.2 and tubulin alpha chain: Solyc08g006890.2 displayed uniform expression during all the stages and hence, were used as controls.

\section{Tomato Yellow Leaf Curl Virus}

Tomato Yellow Leaf Curl Virus (TYLCV) is a monopartite geminivirus complex which belongs to the genus Begomovirus of the family Geminiviridae. EPPO code for the virus is TYLCV0. White fly Bemisiatabaci is the causal organism for TYLCV but potential seed transmission of TYLCV is also noted in tomato. It is among 'top ten' pathologically important plant virus. TYLCV has a singlestranded circular DNA genome of $2.8 \mathrm{~kb}$ which is encapsidated in a twinned icosahedral virion. TYLCV cause plant stunting, leaf curling and yellowing hence severe yield losses. Other than tomato, TYLCV hosts pepper (Capsicum species) common beans (Phaseolus vulgaris) cucurbit (Cucumins species) and estoma (Eustoma grandiflora). TYLCV was first reported in Middle East in 1931. TYLCV is prominent in tropical and subtropical regions (Kil et al., 2016).

The 2787 nucleotide long genome of TYLCV encodes two large open-reading frames (ORF) on viral strand namely $\mathrm{VI}$ and $\mathrm{V} 2$, four on complementary strand namely C1to $\mathrm{C} 4$. V1 
encodes coat protein and V2 encodes proteins for virus movements and suppression of host defense response. $\mathrm{C} 1$ encodes replication associated protein, $\mathrm{C} 2$ transcriptional activator protein, $\mathrm{C} 3$ a replication enhancer and $\mathrm{C} 4$ a movement determinant. TYLCV has been reported to cause $5-100 \%$ infectious tomato plants in India, 20\% tomato yield loss in USA, 30-100\% in the Caribbean Islands, Mexico, Central Amerca, Venezuela and $100 \%$ in Jamica (CABI, 2020).

The transcriptome of TYLCV resistant $S$. habrochaites (R) and susceptible cultivars $S$. lycopersicum (S) was analyzed by Sade et $a l .,(2013,2015)$. The resistant \& susceptible samples responded differently during the diseased condition. The resistant cultivar showed proper fruit development and low virus content. The susceptible cultivar was found devoid of fruits and showed disease symptoms. Four loci which are linked to the TYLCV resistance namely Ty-1/Ty-3 and Ty4 in S. chilense, Ty-2 in S. habrochaites, Ty-5 in $S$. peruvianum were identified. Total 69 genes were found to be expressed in TYLCV $\mathrm{R}$ plant before and upto 7 days after infection (Eybishtz et al., 2009). The transcriptome of $\mathrm{S}$ and $\mathrm{R}$ plants were compared to analyze the changes in LeHT1, the hexose transporter gene. The transcriptome of LeHT1 silenced plants was similar to the TYLCV resistant plants. This revealed that LeHTI confers upon the TYLCV resistance all together with other genes rather than responding directly to the stress. R-software was used to carry out statistical analysis (www.r-project.org). Homologous of resistant and susceptible genes in tomato were identified in Arabidopsis at $\mathrm{p} \leq 0.05$ and fold change of $\geq$ 1.3. Here, 441 putative metabolites were found to be matched with the databases like KEGG, CHEBI and KNAPSACK.

Transcriptional changes in a TYLCV resistant (CLN2777A) and a susceptible (TMXA48-4-
0) breeding line of tomato during TYLCV infection were highlighted (Chen et al., 2013). RNA of these samples wasextracted and the cDNA libraries were sequenced on HiSeq 2000 sequencer, Illumina. The raw sequencing data was submitted to NCBI Sequencer Read Archive under accession number SRP028618. These raw reads were preprocessed by Fast QC to remove the lowquality reads and then mapped to the tomato genome using spliced read mapper Tophat $\mathrm{v}$ 2.0. Transcript abundance and differential gene expression were calculated with the program Cufflinks. Gene fragments were normalized with fragments per kilo base of exons per million mapped reads (FPKM) values. Five genes were validated by RTPCR. These genes were associated with pathogen resistance. The defense response of resistant and susceptible lines was unique as 209 and 807 genes differentially expressed in the resistant and susceptible lines respectively. The proportion of upregulated DEGs was higher in resistant line $(58.37 \%)$ than in susceptible line (9.17\%). However, 38 DEGs were common in both the lines but all down-regulated in susceptible line and 11 genes were up-regulated in the resistant lines. Gene ontology showed higher expression of genes responsible for catalytic activity. The functional classes of DEGs were analyzed through Blast2GO gene ontology software. Resistant and susceptible lines yielded $67.46 \%$ and $63.69 \%$ of DEGs, respectively. There were $30.50 \%$ of total DEGs involved in cellular functions in susceptible line while only $23.04 \%$ in resistant lines. Higher number of DEGs in resistant lines were observed for developmental processes and multicellular organismal processes than in susceptible lines. Hence, the resistant line has certain gene interaction which enables to compete against the stress. There were few DEGs involved in cell killing, cell proliferation, nitrogen utilization and growth in susceptible lines and rhythmic processes in resistant lines. 
In the molecular function class many DEGs were found for catalytic activity. DEGs for nucleic acid binding transcription factor activity and antioxidant activity were specific to susceptible lines only. DEGs for protein binding transcription factor activity were found only in resistant lines. Several DEGs were found exclusively for symplast and cell junction in susceptible lines. There were 16 WRKY genes identified as down-regulated DEGs in susceptible lines whereas seven WRKY genes found up-regulated in resistant lines.

\section{Fungi}

The impacts of early and mild biotic stress in Biogenic Volatile Organic Compound (BVOC) emissions from tomato were investigated (Kasal-Slavik et al., 2017). Tomato was exposed to fungus Botrytis cinerea and Oidium neolycopesici. Aphid Myzuspersicae was also used as biotic stress agent. Then the tomato plants were treated with methyl jasmonate to identify BVOC emissions related to jasmonic acid (JA) signaling pathway activation. Tomato plant was found to activate JA pathway upon infection wihB. cinereaas changes in BVOC emissions were observed.

Functional gene changes in tomato genotypes resistant and susceptible to Verticillium dahlia through RNA-Seq was studied by Tan et al., (2015) studied for roots. RNA was extracted from the tomato roots at two days after infection of $V$. dahlia. The mRNA libraries were sequenced on Illumina sequencer and $2 \mathrm{~GB}$ data was processed. High quality reads i.e., with Q30 (80\%) were used for further processing. All the clean reads were aligned to the genome of tomato by TopHat (V 2.0). Cufflinks program was used to look for transcript abundance and differential gene expression. FDR threshold $\leq 0.01$ and Fold change $\geq 2$ were selected. Total 1,985 DEGs were identified, among which 1,953 (98.39\%) were assigned by $\mathrm{Nr}$ (Non-redundant), 1,579 $(79.55 \%)$ by Swiss-Prot, $1,739(87.71 \%)$ by GO (Gene Ontology), 862 (43.43\%) by COG (Cluster Orthologous Group) and 380 (19.14\%) by KEGG. The data obtained here was deposited in the NCBI SRA database (SRX1022130) in the form of high quality data. ' $\mathrm{G}+\mathrm{C}$ ' content was above $40 \%, 89.15 \%$ sequences of control and $71.04 \%$ of treated samples were aligned to the tomato genome. Total 87 KEGG pathways were assigned and were found associated with phenylpropanoid metabolism and plant pathogen interaction.

\section{Early Blight}

Early Blight is caused by Alternariasp. which is air borne and soil inhabiting fungi. The disease on foliage is leaf blight, on stem is collar rot and on fruit is fruit rot. Thus, all plant developmental stages are crucial for this fungus. Early Blight occurs through-out the world. Warm climate, long nights and dew affects are favorable for the fungi. The spores may enter a plant system through wounds. Spores of Early Blight survive on plant debris and are spread by wind and rain. Tomato yield loss incurred due to Early Blight is 15$100 \%$. Conventional methods of prevention include preventing long duration leaf wetness, sanitation and application of fungicides. The transcriptome to the infected crop may reveal the disease at an early stage. Hence, transcriptomics of Early Blight infected tomato is very significant.

Differentially expressed miRNA and mRNA during Early blight through next generation sequencing was studied (Sarkar et al., 2017). IlluminaTrueSeq RNA library protocol was followed. The quality check was done by SeqQC. The sequence was deposited in GEO database, accession number GSE75922 and GSE75923. Tools like Tophat-2.0.72 and Cufflinks-2.0.14 were used for the transcript 
assembly. Cuffdiff was employed to find the significant changes in the transcript expression i.e., DEGs. Gene Ontology was extracted by BiNGO of Cytoscape v3.2.1 FDR $\leq 0.05$. The miRNA sequences were aligned to tomato unigene library by using psRNATarget (plant small RNA Target Analysis Server). Total 52 miRNA were protruding among them, 39 were down regulated and 13 were up regulated. Seven novel miRNA were significant as well as differentially expressing $(P \leq 0.05)$. Results showed that 3,154 genes in 17 major molecular functions, 62 genes for three different cellular components and 57 genes for biological process. KEGG analysis showed 5,080 genes for 334 different pathways. Here, 24 pathways were found to be significant for Alternaria stress. Differentially regulated genes were found for biosynthesis of ethylene, salicylic acid, jasmonic acid, abscisic acid, ROS activity, NB-LRRs and WRKY transcription factors.

\section{Transcriptomic analysis of pollen developmental stages of tomato}

Pollen carries haploid genetic material to the next generation. The developmental stages of pollen are among important stages of a plant. Tetrad (microspore) formation takes place after meiosis I and II of pollen mother cell. Bicellular pollen results after mitosis I. Plant reproductive organs are often more prone to damage at high temperature or stress than vegetative organs. Tomato fruit development is impaired at high temperature.

The most sensitive flowering phases are meiosis and fertilization. Heat stress during meiotic phase may lead to reduction in pollen fertility and reduction in germination and non vibal pollen tube. Though, heat sensitivity differs among tomato cultivars. Pollen should withstand stress and drying to ensure the healthy plant. Transcriptome and proteome of pollens from tomato flower buds at tetrad $(\mathrm{T})$, post-meiotic (PM) and mature (M) stage under control (C) and heat stressed (HS) conditions were evaluated (Keller et al., 2018). RNA was isolated with MachereyNagel Nucleospinmi RNA isolation kit. RNAs > 200nt were selected for the further analysis. MACE (Massive analysis of cDNA ends) libraries were prepared according to protocol of Bokszczanin et al., (2015).cDNA was synthesized using Life science technologies kit. Bioruptor was used for fragmentation of the cDNAs. Sequencing was done using Illumina HiSeq2000. Sequences were aligned by Next Gen Map (version 0.4.12). Quantification of the transcripts was done by gff files of tomato with HTSeq Python. PCA was derived by Rpackage Facto MineR (version 1.33). The LCMS/MS libraries were screened against SGN (Sol Genomics Network) tomato proteome and were quantified by using MaxQuant. Transcripts for T, PM, M, C and HS were $11,000,9,000,5,000,12,606$ and 12,684 respectively. In control samples, 4,538 genes were common in all the pollen stages and for heat stress the number was 4,332. There were 957 protein groups in C and 1,062 in HS.

During PCA analysis, PC1 showed 52.3\% of the variance inherent in the data which was an indicator of separation among the stages. PC3 showed slight separation for $\mathrm{C}$ and HS, during tetrad stage. In LCMS/MS library, PC1 carried $24.5 \%$ of the variance. Here, PC2 revealed no better separation of the developmental stages in transcriptome as well as proteome study. In overlapped matrix, two translation modes were displayed namely, direct translation and delayed translation. 'Direct translation' means increased transcript levels along with increased protein levels in the same developmental stage. 'Delayed translation' implies increase in protein levels is postponed by one developmental stage but there is increase in the transcript level. 
Total 54 and 108 genes were found in direct and delayed translation, respectively, in $\mathrm{T}$ (tetrad). Delayed translation showed 223 genes in PM and direct translation showed 53 genes in $\mathrm{M}$. KOG annotation stated that $\mathrm{T}$ had expressions for chaperones, protein turnover, Hsp90s, Hsp70 (BIP4), sHsp (Hsp23.8-MI), carbohydrate metabolism, lipid metabolism, nucleic acid metabolism and secondary metabolites. Many genes showed 'delayed translation' in tetrad, namely genes for Hsp100, Hsp70, chromatin structure, disulfide isomerases and few subtilisin-like proteases. Genes for carbohydrate metabolism, energy metabolism, lipid metabolism, secondary metabolites and nucleotide metabolism possessed 'direct translation'. Delayed translation of genes for chromatin structure indicates the chromatin remodeling in postmeiotic stage of pollen.

\section{Transcriptomic analysis of hormone effect on tomato}

Leaf development depicts the overall plant vigour. Hormones are regulators for leaf development. Hormone governs the physiological activities in plants. The coordination between different hormones and plant parts is required for a healthy plant. They are produced in small amount and in some part of the plant to regulate the plant responses. Auxin regulates the leaf phyllotaxis, initiation from shoot apical meristem, serration, margin formation and lobe formation. Misclocalization or misexpression of uxin causes simplified leaves in tomato. Gibberellins (GA) promote seed germination, stem elongation, tricome d/evelopment, pollen maturation and flowering. GA controls cell proliferatio, expansion and leaf complexity. Cytokinin (CK) promote morphogenesis and senescence. Exogenous $\mathrm{CK}$ has little effect on morphogenesis while endogenous application is vital in tomato. Jasmonic acid, absiscic acid, ethylene and strigolactones are also imperative hormones in tomato plant growth (Shwartz et al., 2016).

The transcriptome of tomato plants treated with IAA, GA24 and IAA+GA24. The RNA quality was analyzed(Zhan et al., 2018). Sequencing was done using IlluminaHiSeq 2500 platform. Mapping was done by HISAT. Expectation maximization was used for gene expression level quantification which includes RSEM and FPKM (Fragment Per Kilobase per Million mapped). Differential expression of genes was done by NOI Seq (R/Bio C Package). Gene ontology was studied by Blast2GO. Functional annotation of all the unigenes was made by WEGO. All the metabolic pathways for all the treatments were drawn by using KOBAS. The protein interaction was correlated by using STRING Database, Cytoscape. Primers were designed by Primer Premier 5 software. Total numbers of raw reads were 564.8 million. Total mapped reads were $93.9 \%$ and uniquely mapped were $79.1 \%$. Clean reads were found at Q20 and above. Sum of $88.6 \%$ were found mapped to exons, $3.6 \%$ to introns and $7.9 \%$ were mapped with intergenic region. Total DEGs in IAA treated tomato samples were 2,326, of which 1,185 were up-regulated and 1141 down-regulated. DEGs in GR24 were 260, of which 168 were up-regulated and 92 down-regulated. DEGs for IAA+GR24 were 1,379 , whereas 1,063 were up-regulated and 316 down-regulated. Genes found to be upregulated only in IAA treated samples were 480, only in GR24 treated samples were 1,021 and in IAA+GR24 treatment were 427. Down-regulated genes during IAA were 852, GR24=23 and IAA+GR24=49. Gene Ontology in IAA treated samples was for Biological processes (single organism process, response to stimulus and microtubule based process); for Cellular component (cell periphery, plasma membrane and cell wall); for Molecular function (oxidoreductases 
activity, acting on glycosyl compounds and hydrolyzing O-glycosyl compounds). GO for GR24 treatment showed negative regulation of catalysis and MF. GO for IAA+GR24 treatment has genes for $\mathrm{BP}$ (response to stimulus, chemical and organic substances); for CC (cell periphery, plasma membrane and extracellular region); and for $\mathrm{MF}$ (Oxidoreductases, sequence specific DNA Binding and Nucleic acid binding).

Network analysis of DEG showed 19 network internodes for IAA, 13 for GR24 and four for IAA+GR24. IAA treated samples showed 27, GR24 treatment: 12 and IAA+GR24:23 KEGG pathways. Six pathways were common in all the three samples. CrtQgene was found to be down-regulated in IAA and IAA+GR24 treated samples. $\mathrm{CrtH}$ was downregulated in IAA samples. Sixteen genes were used for the process of validation.

The transcriptome of the tomato leaves in response to ABA treatment was examined (Wang et al., 2013). ABA treated and controlled tomato RNA samples were subjected to deep sequencing using IlluminaHiSeq 2000. The sequencing gave 20.95 GB of clean data. Adapters were removed by SeqPrep (github.com /jstjhon/SeqPrep).

Sequence mapping was done by Tophat and assembled by Cufflinks. The sequence alignment was done by SOAPaligner/soap2 software (soap.genomics.org.cn) and $81.97 \%$ sequences matched to unique $(36.53 \%)$ and multiple $(45.44 \%)$ genomic locations. The sequences were merged with Cuffmerge. Total $90.02 \%$ of transcripts possessed ORF.

The data obtained had high homology with NCBI non-redundant protein database. There were genes for salinity, drought and cold tolerance. The largest group with regulatory protein was the 'transcription factors'.
Blast2GO was used for transcript classification. Gene Ontology gave total 31,107 transcripts, 23 groups for biological processes, 19 for cellular components and 15 for molecular functions.

In controlled samples, 38,626 transcripts were expressed and in ABA treated those were 37,989. The transcription factors (TF families) identified were, bZIP (111 transcripts), Bhlh (146), MYB (212), AP2/ERF (84), NAC (63) and WRKY (81). 41 Heat shock factors (HSFs) and 61 MADS-boxes were also detected. Differential expression was studied using edgeR. Gene ontology was done by Blast2GO. COG was done by Blastx 2.2.24+STRING 9.0. Metabolic pathways were studied using KEGG.

Genes related to ABA pathway were $\mathrm{ABA}$ signaling transduction (PYP/PYL, PP2C,SnRK2, ABF), bZIP(ABRT), BHLH (DREB), MYB (MYC), AP2 (AP2/ERF), NAC, WRKY, HSF and MADS-box. MYB had the highest up-regulation (66), BHLH had 47, bZIP 40, WRKY and NAC recorded 33 and 23 respectively. All the genes related to heat shock proteins were Hsp 90, Hsp 70, Shsp, CAT and SOD; for ROS scavenging system: GLR, APX, MDAR, HAR, GST, GPX, POD, Txr and Prxr; for pathogens resistance were PAL, PPO, GLU, chitinase, TGA, PR1, JAR1, JAZ, ETR and ERF/EREBP.

\section{Interactive transcriptome of abiotic and biotic stress in tomato}

Tomato root transcriptome under water stress, fungal infection and nematode invasion was studied (Balestrini et al., 2019). Arbuscularmycorrhizal (AM) fungus was Rhizophagusintraradicesand nematode was Meloidogyne incognita. Tomato cultivar namely 'San Marzanonano' (S. lycopersicum) was taken under the study. Tomato roots were 
compared as non-fungal colonized (C, control), fungal colonized (AM), fungal colonized and water stressed (AM_WS), nematode infected (RKN), nematode infected and fungal colonized (RKN_AM). Sequencing gave $187,7 \times 10^{6}$ reads. Reference genome used for mapping was SL2.40.26 ( $S$. lycopersicum). Higher numbers of genes were differentially up-regulated in AM (12\%) than in RKN (10\%). Gene ontology for AM_WS and RKN_AM was done for response to oxidative stress, peroxidase activity and heme binding.

Molecular functional genes in AM_WS were found to be up-regulated for transcription regulatory activity while metabolic process related genes in RKN_AM were up-regulated for protein ubiquitination and protein amino acid phosphorylation. Cellular component was over-represented by gene for microtubule based moment. Five out of total six genes for putative ripening related proteins (RRP) were highly up-regulated in AM colonized (unstressed) and water stressed tomato samples.

Blue copper proteins, germin-like proteins, glutathione-S-transferase and cell wall related genes were significantly up-regulated in AM fungal infected samples. Blue copper binding genes are considered markers for AM colonization in plants. AM symbiosis was found completely function in water stressed tomato roots (AM_WS). Genes for cytochrome P450 (CYPs) were highly upregulated in AM_WS tomato root samples. CYPs are known for sterol biosynthesis and production of secondary metabolites.

\section{Pan-transcriptome of tomato}

Pan-transcriptome of 399 tomato accessions by analysing differentially expressed genes (DEGs) and global expression presence/absence variation (ePAV) was constructed (Dan et al., 2020). Genes that are expressed only in a specific group are called as ePAV. The study contained 26 accessions of S. pimpinellifolium (PIM), 114 accessions of S. lycopersicum var. cerasiforme(CER) and 259 accessions of big fruited S. lycopersicum (BIG). The reference genome was SL3.0. The average mapping rate was $93.35 \%$ however, the mean mapping rate for PIM, CER and BIG was $90.26 \%, 93.03 \%$ and $93.80 \%$, respectively. The lower mapping rate in PIM group shows that there is lack of genes in Heinz 1706 (SL3.0) genome when compared to S. pimpinellifolium (PIM). Thus few genes have been eliminated during the selection procedure.

Unmapped genes in all the accessions were assembled de novo. This assembly gave 82,$617 ; 1,48,156$ and 1, 60,347 transcripts in PIM, CER and BIG, respectively. Total 907 (PIM), 2,328 (CER) and 3,946 (BIG) highconfidence RTAs were absent from Heinz 1706.Genes which were expressed in PIM group but not in CER or vice versa were ePAV genes during tomato domestication.

Hence, genes expressed in CER group but not in BIG or vice versa are were ePAV genes during tomato breeding. These genes are identified by orthologous gene clustering. Total 6,123 RTAs orthologous clusters were identified among which 5,261 were singlecopy clusters.

Here, 2,678 ePAV RTAs clusters were identified (2,706 ePAV genes, 640 genes lost expression, 2,066 gained expression) during domestication. Similarly, 4,970 ePAV RTAs clusters were identified (4,992 ePAV genes, 1,692 genes lost expression, 3,300 gained expression) during tomato breeding. Total 3,629 genes were found to be significant during tomato selection process, and 19 of these were associated with reduced fruit total soluble solid (TSS) in recent cultivars. 
"Next gen" RNA-Seq provides opportunity for genome wide survey in unbiased manner. Though per-sample cost is high at the beginning but the depth is much more in comparison to micro-array. Real-time quantitative PCR requires primer designing and micro-array is dependent on probes. While RNA-Seq is free from all these limitations. RNA-Seq sequencing is supplied by Illumina, Nanopore, Applied Bioscience etc whereas Micro-array chip can be customized by companies like Affymetrix, Agilent Technologies, BD Bioscience, BioRad, Biogenex, Illumina, Life technologies and Qiagen. Life science, Quagen AB gene, Applied Biosystems, Biogen,BioRad, Eppendorf and Invitrogen are reliable companies for real-time PCR system.

Variants for RNA-Seq are HiSeq, MiSeq and QuartzSeq. Species specific as well as stress specific microarray chips can be designed using pre-defined probes. Chemistry for RNA-Seq is sequencing by synthesis while microarray works on the principle of hybridization of complementary sequences. TaqMan probe, TAMRA, ROX, Scorpion and SYBR Green chemistry are exemplary in realtime PCR (Table 4).

According to Boston University, Medical Campus Microarray and Sequencing Resource, transcriptome technologies though microarray chip and RNA sequencing can be grouped in to low (100-300\$), medium (300$700 \$$ ) and high (above 700 \$)price range products, per application. Low price range products includes IlluminaTrueSeq,NEBNext and Kapa RNA HyperPrep. Medium price range products are miRNA 4.0, Human transcriptome, Human Exon, Mouse transcriptome, Rat transcriptome and Arabidopsis array. The highest price range is for IlluminaNextSeq 500 (150 \& 300 cycles) and high output (75, 150 and 300 cycles) (Table 5).
Manual RNA extraction protocol viz. with Trizol as well as RNA isolation by kit such as Macherey-Nagel, RNAOut, Green spin, RNeasy, and ZR are constantly uses by the researchers. The literature shows that Illuminasequencins is the most exploited tool for sequencing. Though few researchers have also used microarray also. Most of the primers are designed by Primer Premier 5, Primer 3, QuantPrime and PrimeQuest. Latest real-time cyclers in use are $\mathrm{AB} 7300 \& 7500$ realtime PCR system, ABI 7900HT, LightCycler 96 Roche Life Science and CFX connect real-time system BioRad. The most expedient bioinformatics tools are Cofflinks, TopHap, Cuffmerg, Ciffdiff, Bowtie, CLCBlast2GO, Trimity and R-Software (Table 6\&7).

- High-throughput sequencing methods give an insight to understand the plant molecular mechanisms during stress condition.

- Next generation sequencing is an efficient method over microarray.

- For the expression under different stages (developmental, infection), transcriptomics reveals biochemical signaling pathways which are related to the plant stress response.

- Genes are categorized in Molecular Function, Cellular Components and Biological Processes.

- WRKY and phenyl propanoid genes impart resistance in tomato plants towards various stresses.

- Differentially expressed transcripts may promote targeting of a candidate gene, which may be used in the breeding programs for resistance or tolerance to certain type of stress.

- Gene expression profiling, genome annotation, miRNA, Transcription Factors and discovery of non-coding RNA, etc. are also employed using transcriptomics. 


\section{Limitations for RNA-Seq}

Transcriptomics is cost effective in long run and with multiple samples. The transcripts found require proper analysis and interpretation through bioinformatics and statistical tools. The human resources in RNA sequencing technology are comparatively less in numbers.

\section{Library preparation}

Library preparation involves many steps to be followed during specified time duration. Following all the steps critically is very significant. The products in-between and after the last step have peculiar storage condition. Micro RNAs, Piwi-interacting RNAs, short interfering RNA are sequenced after adaptor ligation but higher RNA (total or mRNAs) molecules are fragmented by hydrolysis or nebulization before sequencing. The cDNA is biased towards sequence identification from 3 ' end, thus the same end is more informative (Wang et al., 2009).

\section{Proper selection of bioinformatics tools}

Diverse bioinformatics tools direct the proper interpretation of data. A set of tools are required to store, retrieve and process the data generated. Data analysis includes removal of adapter sequence, quality enhancement, mapping, annotation, gene enrichment, pathway identification, gene ontology and differential gene expression. Identification of unique splicing events which are occurring between two distant sequences and sequences flanked by exons of diverse genes is a decisive task. Short reads with high copy number and long repetitive sections demand more efforts.

\section{Cost and coverage}

Sequencing depth is proportional to the coverage. Depth allows identification of rare variants. Deep sequencing has larger genome, complex transcriptome and higher coverage data and hence, higher cost. Though, the cost is competent over arrays.

\section{Way ahead}

The era is demanding an easy though specific approach to transcriptomics. The institutions with a full facilitated laboratory should design abundant projects on abiotic and biotic stress resistance for model crops as well as for novel crops. The developing countries should be focused more and more as they have saturating population rise. Easy access to various bioinformatics and statistical tools may pave the way for informal approach of transcriptomics. As these days, researchers are having huge data sets but they may require proper application of bioinformatics tools. Organizing workshops for these tools and generating technically well qualified human resources may be fruitful. Targeted genes after differential expression should be directed for gene editing transformation. The comparison of transcripts of wild and cultivated species is the treasure of resistant genes.

\section{Compliance with ethical standards}

Funding: The manuscript is a review paper hence funding is not applied.

Conflict of interest: Author1 declares that she has no conflict of interest.

Author 2 declares that he has no conflict of interest.

Ethical approval: This article is a review and does not contain any studies with human or animal participants performed by any of the authors. 
Table.1 Botanical classification of tomato

\begin{tabular}{|l|l|}
\hline Kingdom & Plantae \\
\hline Clade & Angiosperms, Eudicots, Asterids \\
\hline Order & Solanales \\
\hline Family & Solanaceae \\
\hline Genus & Solanum \\
\hline Species & Solanum lycopersicum $\mathrm{L}$ \\
\hline Chromosome no. & $2 \mathrm{n}=2 \mathrm{x}=24$ \\
\hline Ploidy level & Diploid \\
\hline Genome size & $950 \mathrm{Mb}$ \\
\hline
\end{tabular}

Table.2 Domesticated varieties, wild varieties and major producers of tomato

\begin{tabular}{|l|l|}
\hline Domesticated species & $\begin{array}{l}\text { Solanum lycopersicum } \\
\text { Wild species }\end{array}$ \\
$\begin{array}{l}\text { Solanum galapagenes, S. pimpinellifolium, S. arcanum, } S . \\
\text { cheesmanie, S. chilense, S. chmielewskii,S. habrochaites, } S . \\
\text { neorickii, S. pennellii, S. peruvianum }\end{array}$ \\
\hline Major producers in the world & China, India, USA, Turkey, Egypt \\
\hline Leading producerstates in India & $\begin{array}{l}\text { AP, Karnataka, MP, Telangana, Gujarat, Bihar, WB, } \\
\text { Maharashtra, Chhatishgarh and HP }\end{array}$ \\
\hline
\end{tabular}

Table.3 Area, production and productivity of tomato (Anonymous, 2018)

\begin{tabular}{|l|l|l|l|}
\hline & Area (Mha) & Production (MMT) & Productivity(MT/ha) \\
\hline World & 5.02 & 170.75 & 34.01 \\
\hline India & 0.78 & 19.37 & 24.84 \\
\hline
\end{tabular}


Table.4 Comparison between Real-time PCR, Microarray and "Next gen" RNA Seq

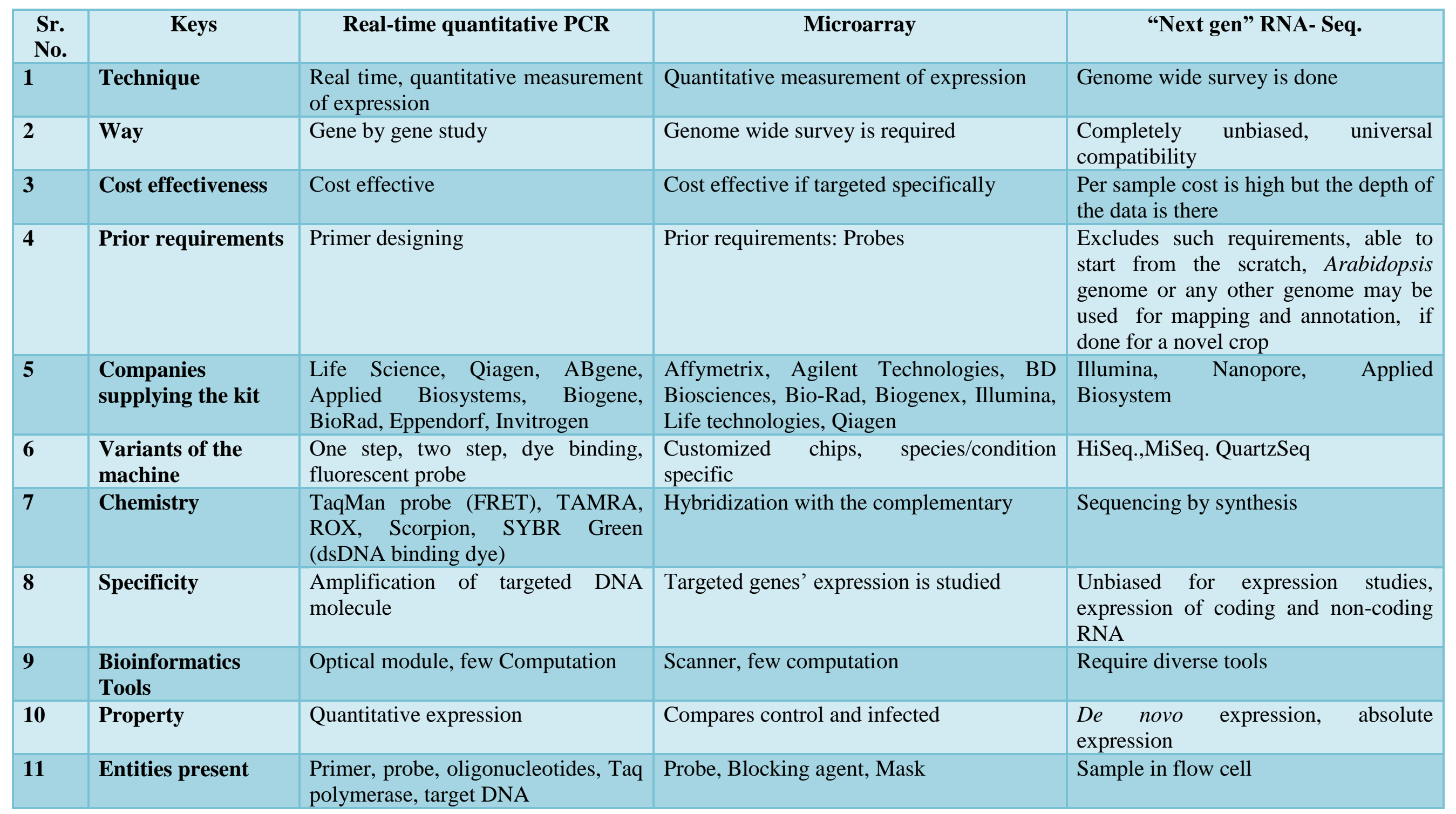


Table.5 Boston University, Medical Campus Microarray and Sequencing Resource (Curtsey: http://www.bumc.bu.edu/microarray/pricing/)

\begin{tabular}{|c|c|c|c|}
\hline $\begin{array}{l}\text { Sr. } \\
\text { No. }\end{array}$ & Applications & $\begin{array}{l}\text { Internal } \\
\text { pricing (\$) }\end{array}$ & $\begin{array}{l}\text { External } \\
\text { Academic } \\
\text { pricing } \$ \text { \$) }\end{array}$ \\
\hline 1 & IlluminaTrueSeq Standard mRNA & 250 & 280 \\
\hline 2 & NEBNext Ultra II RNA & 225 & 255 \\
\hline 3 & IlluminaTrueSeq Standard Total RNA & 300 & 330 \\
\hline 4 & Kapa RNA HyperPrep & 290 & 320 \\
\hline 5 & IlluminaTrueSeq Small RNA & 320 & 350 \\
\hline 6 & NEBNext Small RNA & 270 & 300 \\
\hline 7 & IlluminaNextera XT (Small Genome) & 135 & 155 \\
\hline 8 & IlluminaNextSeq 500150 cycles $(130 \mathrm{M})$ & 1600 & 1700 \\
\hline 9 & IlluminaNextSeq 500300 cycles $(130 \mathrm{M})$ & 2300 & 2400 \\
\hline 10 & High Output 75 cycles $(400 \mathrm{M})$ & 1900 & 2000 \\
\hline 11 & High Output 150 cycles $(400 \mathrm{M})$ & 3250 & 3350 \\
\hline 12 & High Output 300 cycles $(400 \mathrm{M})$ & 5100 & 5200 \\
\hline 13 & Ion Torrrent PGM 314 (400-700K) & 630 & - \\
\hline 14 & Ion Torrrent PGM 316 (2-3.5M) & 790 & - \\
\hline 15 & Ion Torrrent PGM 318 (3-5M) & 950 & - \\
\hline 16 & miRNA 4.0 (Multispecies) (Affymetrix) & 335 & 355 \\
\hline 17 & Human Transcriptome 2.0 Array (Aff.) & 500 & 530 \\
\hline 18 & Human Exon 1.0 ST Array (Aff.) & 665 & 695 \\
\hline 19 & Mouse Transcriptome 1.0 Array (Aff.) & 500 & 530 \\
\hline 20 & Mouse Exon 1.0 ST Array (Aff.) & 665 & 695 \\
\hline 21 & Rat Transcriptome 1.0 Array (Aff.) & 500 & 530 \\
\hline 22 & Arabidopsis 1.0ST Array (Aff.) & 415 & 445 \\
\hline 23 & C. elegans 1.0ST Array (Aff.) & 415 & 445 \\
\hline 24 & Drosophila 1.0ST Array (Aff.) & 415 & 445 \\
\hline 25 & Rhesus 1.0ST Array (Aff.) & 415 & 445 \\
\hline 26 & Zebrafish 1.0ST Array (Aff.) & 415 & 445 \\
\hline 27 & Yeast Genome 2.0 Array (Aff.) & 440 & 470 \\
\hline 28 & E. coli Genome 2.0 Array (Aff.) & 475 & 505 \\
\hline 29 & AribidopsisGenome 2.0 Array (ATH1) (Aff.) & 540 & 570 \\
\hline 30 & Drosophila Genome 2.0 Array(Aff.) & 515 & 545 \\
\hline
\end{tabular}


Table.6 Methodology used by various researchers for transcriptomics in tomato

\begin{tabular}{|c|c|c|c|c|c|c|}
\hline $\begin{array}{l}\text { Sr. } \\
\text { No. }\end{array}$ & Author (Year) & $\begin{array}{l}\text { RNA/DNAisolation } \\
\text { and Library } \\
\text { preparation }\end{array}$ & $\begin{array}{l}\text { Transcriptome } \\
\text { technology }\end{array}$ & $\begin{array}{l}\text { Primer designing, } \\
\text { RT-PCR }\end{array}$ & Bioinformatics tools & $\begin{array}{l}\text { Reference genome and } \\
\text { database used }\end{array}$ \\
\hline 1 & $\begin{array}{l}\text { Koeing et al., } \\
2013\end{array}$ & Trizol, RNeasy kit & $\begin{array}{l}\text { Illumina GA II, } \\
\text { HiSeq } 2000\end{array}$ & - & R-stastical programming & Heinz, Potato \\
\hline 2 & $\begin{array}{l}\text { Keller et al., } \\
2013\end{array}$ & $\begin{array}{l}\text { Macherey-Nagel } \\
\text { miRNA isolation kit, } \\
\text { MACE }\end{array}$ & $\begin{array}{l}\text { IlluminmaHiSeq } \\
2000\end{array}$ & - & $\begin{array}{l}\text { Next Gen Map, HTSeq } \\
\text { Python, Facto MineR R- } \\
\text { package, MaxQuant, } \\
\text { KOG }\end{array}$ & $\begin{array}{l}\text { SGN, ITGA2.4 } \\
\text { (International Tomato } \\
\text { Annotation Group, Sol } \\
\text { Genomics Network) }\end{array}$ \\
\hline 3 & $\begin{array}{l}\text { Wang et al., } \\
2013\end{array}$ & Trizol, TruSeq & $\begin{array}{l}\text { IlluminmaHiSeq } \\
2000\end{array}$ & Primer Premier 5 & $\begin{array}{l}\text { SeqPrep, TopHat, } \\
\text { Cufflinks, Trinity, } \\
\text { SOAPaligner, } \\
\text { Cuffmerge, Blas } 2 \mathrm{GO}, \mathrm{R} \\
\text { software }\end{array}$ & $\begin{array}{l}\text { ITAG2.3, , NCBI NR, GO, } \\
\text { STING, KEGG }\end{array}$ \\
\hline 4 & $\begin{array}{l}\text { Chen et al., } \\
2013\end{array}$ & RNAOut kit, TrueSeq & $\begin{array}{l}\text { IlluminmaHiSeq } \\
2000\end{array}$ & $\begin{array}{l}\text { Primer Pemier5, } \\
\text { qTOWER 2.0/2.2 }\end{array}$ & $\begin{array}{l}\text { FastQC, TopHat, } \\
\text { Cufflink, Blast } 2 \mathrm{GO}\end{array}$ & Heinz 1706 \\
\hline 5 & $\begin{array}{l}\text { Sade et al., } \\
(2013,2015)\end{array}$ & Tri-Reagent method & Microarray & $\begin{array}{l}\text { QuantPrime, } 7300 \\
\text { Real Time PCR } \\
\text { System }\end{array}$ & R software & $\begin{array}{l}\text { KEGG, CHEBI and } \\
\text { KNAPSACK }\end{array}$ \\
\hline 6 & $\begin{array}{l}\text { Aflitos et al., } \\
2014\end{array}$ & $\begin{array}{l}\text { DNA isolation protocol } \\
\text { (Van der Beek et al., } \\
\text { 1992) }\end{array}$ & $\begin{array}{l}\text { IlluminmaHiSeq } \\
2000\end{array}$ & - & $\begin{array}{l}\text { Bwotie, CLC, Clustal W, } \\
\text { SNPEFF, SAMTOOLS, } \\
\text { CLC, ALLPATHS, } \\
\text { SCARPA, Clustal w }\end{array}$ & Heinz v 2.40, ITAG 2.4 \\
\hline 7 & $\begin{array}{l}\text { Tan et al., } \\
2015\end{array}$ & Trizol method & $\begin{array}{l}\text { IlluminmaHiSeq } \\
2000\end{array}$ & $\begin{array}{l}\text { DNAMAN 6, } \\
\text { ABI 7900HT }\end{array}$ & $\begin{array}{l}\text { TopHat, Cufflink, } \\
\text { BLAST }\end{array}$ & SwissProt, KEGG, COG \\
\hline 8 & Ye et al., 2015 & $\begin{array}{l}\text { Green spin RNA quick } \\
\text { extraction, mRNA Seq }\end{array}$ & IlluminaAnalyzerIIx & Primer 3 & $\begin{array}{l}\text { TopHat, EdgeR, DAVID, } \\
\text { CORREL }\end{array}$ & $\begin{array}{l}\text { SL2.40, SOL Genomics, } \\
\text { Tomato Functional } \\
\text { Genomic Database } \\
\text { (TFGD) }\end{array}$ \\
\hline
\end{tabular}




\begin{tabular}{|c|c|c|c|c|c|c|}
\hline 9 & $\begin{array}{l}\text { Lovieno et al., } \\
2016\end{array}$ & Trizol method, TruSeq & $\begin{array}{l}\text { IlluminmaHiSeq } \\
1500\end{array}$ & ABI 7900HT & $\begin{array}{l}\text { Trim Galore, Cutadapt, } \\
\text { FastQC, Bowtie, TopHat }\end{array}$ & Tomato genome $\mathrm{v} 2.40$ \\
\hline 10 & $\begin{array}{l}\text { Dia et al., } \\
2017\end{array}$ & - & - & - & $\begin{array}{l}\text { FastQC, TopHat, } \\
\text { Cuffmerge, Cuffdiff, } \\
\text { KOBASS }\end{array}$ & $\begin{array}{l}\text { SRA } \\
\text { (Koeing et al., 2013) }\end{array}$ \\
\hline 11 & $\begin{array}{l}\text { Kumar } \\
\text { \&Chattopadhy } \\
\text { ay et al., } 2017\end{array}$ & - & - & - & & $\begin{array}{l}\text { EBI } \\
\text { (Aflitos et al., 2014) }\end{array}$ \\
\hline 12 & $\begin{array}{l}\text { Sarkar et al., } \\
2017\end{array}$ & Trizol, TruSeq & IlluminmaTrueSeq & AB 7500 FAST & $\begin{array}{l}\text { SeqQC, TopHat } 2 \text {, } \\
\text { Cufflinks, Cuffdiff, } \\
\text { BiNGO, KEGG }\end{array}$ & psRNATarget \\
\hline 13 & $\begin{array}{l}\text { Rahim et al., } \\
2018\end{array}$ & $\begin{array}{l}\text { RNeasy mini kit, } \\
\text { TruSeq }\end{array}$ & $\begin{array}{l}\text { IlluminmaHiSeq } \\
2000\end{array}$ & $\begin{array}{l}\text { LightCycler } 96 \\
\text { Roche Life } \\
\text { Science }\end{array}$ & $\begin{array}{l}\text { TopHat, Cufflink, } \\
\text { DESeq }\end{array}$ & SwissProt, KEGG \\
\hline 14 & $\begin{array}{l}\text { Razali et al., } \\
2018\end{array}$ & $\begin{array}{l}\text { ZR Plant RNA mini kit, } \\
\text { Zymo, } \\
\text { NEBNext }\end{array}$ & $\begin{array}{l}\text { IlluminmaHiSeq } \\
2000\end{array}$ & - & $\begin{array}{l}\text { Trimmomatic, Trinity, } \\
\text { TransRate,BUSCO, } \\
\text { InterProscan, } \\
\text { OrthoMCL, BWA, } \\
\text { CIROS, SAMtools, } \\
\text { DEAP }\end{array}$ & SwissProt \\
\hline 15 & $\begin{array}{l}\text { Shukla et al., } \\
2018\end{array}$ & Trizol method & $\begin{array}{l}\text { IlluminmaHiSeq200 } \\
0\end{array}$ & $\begin{array}{l}\text { PrimerQuest, CFX } \\
\text { connect real-time } \\
\text { system }\end{array}$ & $\begin{array}{l}\text { CASAVA, TopHat, } \\
\text { PANTHER, BLASTX, } \\
\text { DESeq2, AgriGO, } \\
\text { MapMan }\end{array}$ & SL2.50, KEGG \\
\hline 16 & $\begin{array}{l}\text { Balestrini et } \\
\text { al., } 2019\end{array}$ & $\begin{array}{l}\text { RNeasy Plant mini kit, } \\
\text { TruSeq }\end{array}$ & $\begin{array}{l}\text { IlluminaHiScanSQ, } \\
\text { SBS v3 kit }\end{array}$ & - & $\begin{array}{l}\text { FastQC, CLC, Edge R, } \\
\text { AgriGO }\end{array}$ & SL2.40.26 \\
\hline 17 & $\begin{array}{l}\text { Dan et al., } \\
2020\end{array}$ & $\begin{array}{l}\text { Quick RNA isolation } \\
\text { kit }\end{array}$ & $\begin{array}{l}\text { IlluminmaHiSeq200 } \\
0\end{array}$ & $\begin{array}{l}\text { Primer3, CFX } \\
\text { manager }\end{array}$ & $\begin{array}{l}\text { Cytoscape, MultiQuant, } \\
\text { SOAP2, SOAPsnp, } \\
\text { BWA, Samtools, } \\
\text { PHYLIP, Hisat2, PEER }\end{array}$ & $\begin{array}{l}\text { NCBI, European } \\
\text { Nucleotide archive. } \\
\text { ITAG2.4, SL3.0 }\end{array}$ \\
\hline
\end{tabular}


Table.7 Technology used for transcriptomics by the researchers

\begin{tabular}{|c|c|c|c|}
\hline $\begin{array}{l}\text { Sr. } \\
\text { No. }\end{array}$ & Author & Trait studied in tomato & $\begin{array}{l}\text { Methodology } \\
\text { performed for } \\
\text { transcriptome }\end{array}$ \\
\hline 1 & Koeing et al., 2013 & Cultivated vs wild species & Illumina sequencing \\
\hline 2 & Keller et al., 2013 & $\begin{array}{l}\text { Pollen developmental } \\
\text { stages }\end{array}$ & Illumina sequencing \\
\hline 3 & Wang et al., 2013 & Effect of hormones & Illumina sequencing \\
\hline 4 & Chen et al., 2013 & TYLCV resistance & Illumina sequencing \\
\hline 5 & Sade et al., 2013\&2015 & TYLCV resistance & Microarray \\
\hline 6 & Aflitos et al., 2014 & Cultivated vs wild species & Illumina sequencing \\
\hline 7 & Tan et al., 2015 & $\begin{array}{l}\text { Verticillium dahlia } \\
\text { resistance }\end{array}$ & Illumina sequencing \\
\hline 8 & Ye et al., 2015 & $\begin{array}{l}\text { Cultivars, days after } \\
\text { flowering }\end{array}$ & Illumina sequencing \\
\hline 9 & Lovieno et al., 2016 & Drought stress & Illumina sequencing \\
\hline 10 & Dia et al., 2017 & Cultivated vs wild species & Illumina sequencing \\
\hline 11 & $\begin{array}{l}\text { Kumar \&Chattopadhyay et al., } \\
2017\end{array}$ & Cultivated vs wild species & Illumina sequencing \\
\hline 12 & Sarkar et al., 2017 & Early Blight & Illumina sequencing \\
\hline 13 & Rahim et al., 2018 & Normal and cherry tomato & Illumina sequencing \\
\hline 14 & Razali et al., 2018 & Salt stress & Illumina sequencing \\
\hline 15 & Shukla et al., 2018 & Nematode resistance & Illumina sequencing \\
\hline 16 & Balestrini et al., 2019 & $\begin{array}{l}\text { Fungus, nematode and } \\
\text { water stress }\end{array}$ & Illuminasequencing \\
\hline 17 & Dan et al., 2020 & $\begin{array}{l}\text { Pan-transcriptome of } \\
\text { tomato }\end{array}$ & Illuminasequencing \\
\hline
\end{tabular}

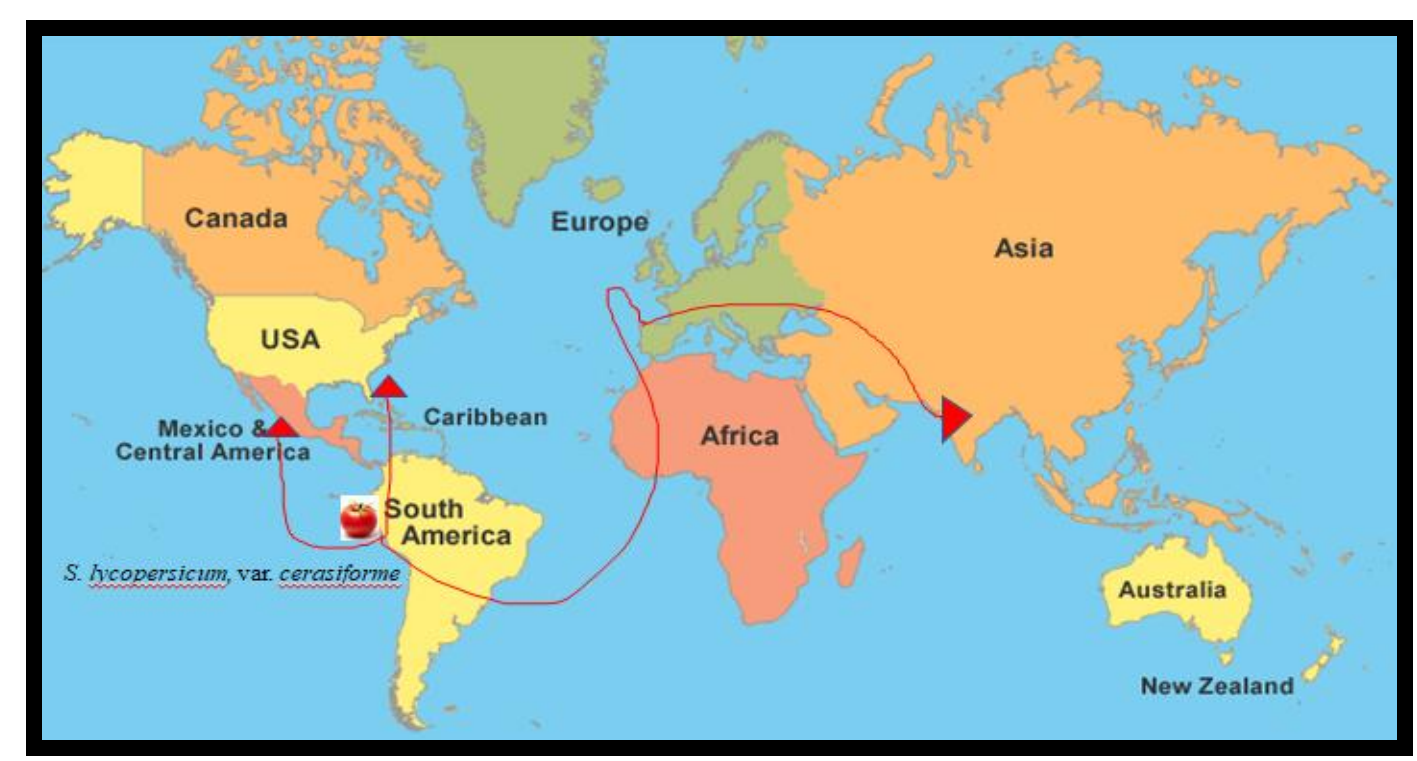

Fig.1 Center of origin of tomato (Simmonds, 1976) 


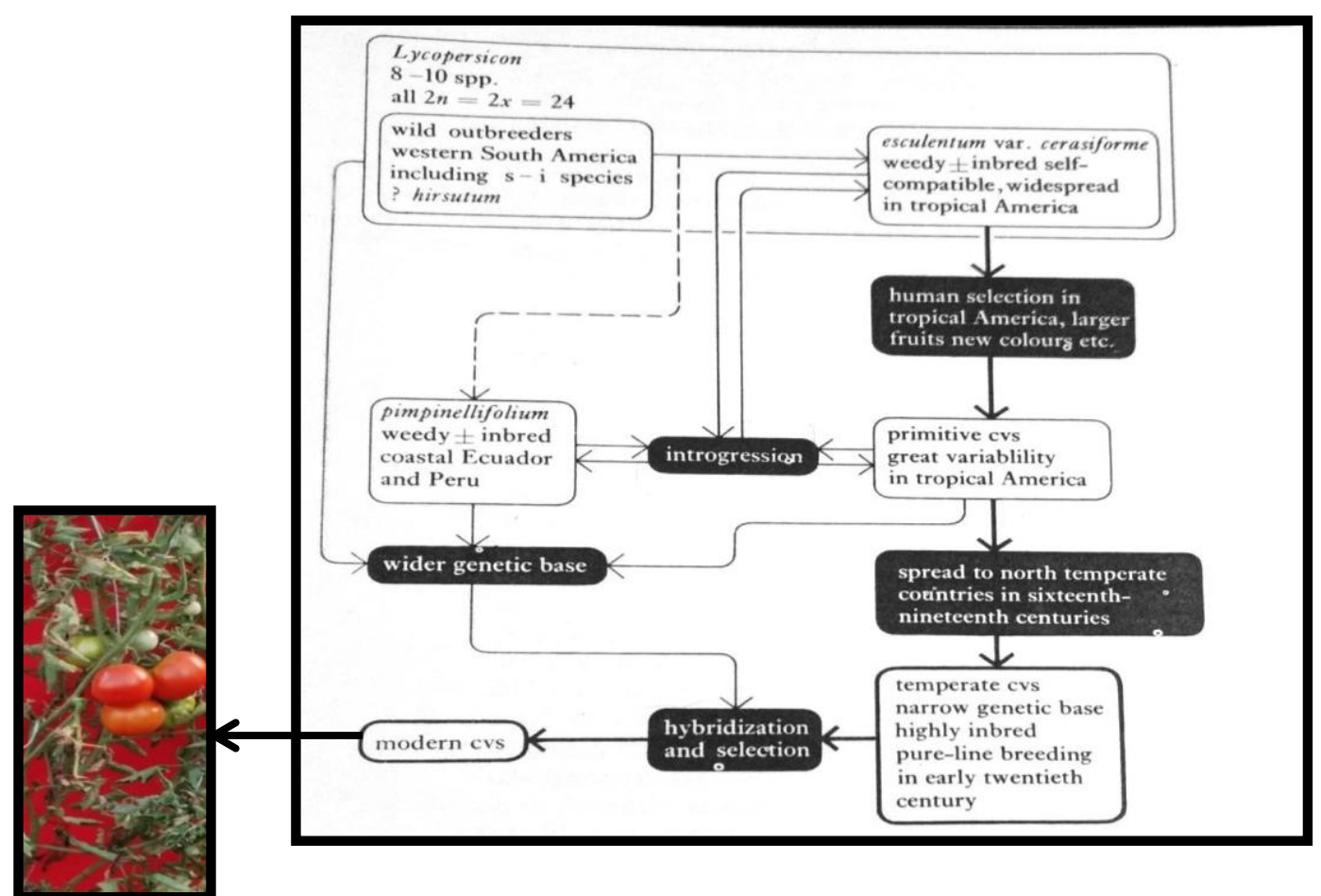

Fig.2 Evolutionary relationships of tomato (Simmonds, 1976)

\section{References}

Anonymous (2014).Biology of Solanum lycopersicum (Tomato).

Anonymous (2018). $3^{\text {rd }}$ Advance Estimates of Area and Production of Horticulture Crops, Department of Agriculture Cooperation \& Farmers Welfare, Krishibhawan, New Delhi.

Balestrini R, Rosso LC, Veronico P,Melillo MT, Luca FD, Fanelli E, Colagiero M, di Fossalunga AS, Ciancio A, Pentimone I (2019) Transcriptiome responses to water deficit and nematode infection in mycorrhizal tomato roots. Front Microbiol 10:1807. doi.org/10.3389/fmicb.2019.01807.

Bokszczanin KL, Krezdorn N, Fragkostefanakis S, Muller S, Rycak L, Chen Y, Hoffmeier K, Kreutz J, Paupiere MJ, Chaturvedi P (2015) Identification of novel small ncRNAs in pollen of tomato. BMC Genomics
16:714.

Bolger M E, Arsova B, Usadel B (2017) Plant genome and transcriptome annotations: from misconceptions to simple solutions. BriefBioinform135:1-13.

CABI (2020).Invasive Species Compendium. Wallingford, UK: CAB International (www.cabi.org/isc).

Capel C, Fernandez del Carmen A, Alba JM M, Lima-Sila V,Hernández-Gras F, Salinas M, Boronat A, Angosto T., Botella MA, Fernández-Muñoz R, Granell A,Capel J (2015) Wide-genome QTL mapping of fruit quality traits in a tomato RIL population derived from the wild-relative species Solanum pimpinellifoliumL. TheorAppl Genet 128:2019https://doi.org/10.1007/s00122 -015-2563-4.

Chen T, Lv Y, Zhao T, Li N, Yang Y, Xu W, He X, Liu T, Zang B (2013) Comparative Transcriptome Profiling of a Resistant vs. Susceptible Tomato 
(Solanum lycopersicum) Cultivar in Response to Infection by Tomato Yellow Leaf Curl Virus. PLos ONE, 8 (11): e80816 doi:10.1371/journal.pone.0080816.

Cheng L, Zou Y, Ding S, Zhang J, Yu X, Cao J, Lu G (2010)Polyamine accumulation in transgenic tomato enhances the tolerance to high temperature stress.Plant Biol 51(5):489-499.

Chetelat, R. T. \&Ji, Y. (2007) GISH analysis of meiotic chromosome pairing in Solanum lycopersicoidesintrogression lines of cultivated tomato. Genome 50: 825-833.

Chetelat RT, Pertuze RA, Faundez L, Graham EB, Jones CM(2009) Distribution, ecology and reproductive biology of wild tomatoes and related nightshades from the Atacama Desert region of northern Chile Euphyticahttp://www.springerlink.com/ content/92072848g7547w41/.

Dan L, Liang Y, Jin-zhe Z, Guang-tao Z, Hong-jun L, Ya-qing L, Yan-ling W, Xue C, Tian-shu S, San-wen H, Yaoyao W (2020) Domestication and breeding changed tomato fruit transcriptome. J IntegrAgric19(1):120132. doi: 10.1016/S20953119(19)62824-8.

Dia Q, Geng L, Lu M, Jin W, Nan X, He P, Yao Y (2017) Comparative transcriptome analysis of the different tissues between the cultivated and wild tomato. PLoS ONE 12(3) e0172411, doi: 10.1371/journal.phone.0172411.

Eybishtz A, Peretz Y, Sade D, Akad F, Czosnek H (2009) Silencing of a single gene in tomato plants resistant to Tomato yellow leaf curl virus renders them susceptible to the virus. Plant MolBiol 71:157-171.

Gorovits R, Czosnek H (2007) Biotic and Abiotic Stress Responses in Tomato Breeding Lines Resistant and
Susceptible to Tomato Yellow Leaf Curl Virus. doi:10.1007/978-1-40204769-5_13.

Haupt-Herting S,Fock HP (2000) Exchange of oxygen and its role in energy dissipation during drought stress in tomato plants. Physiol Plant 110:48995.

Iberkleid I, Sela N, BrownMS (2015) Meloidogyne javanica fatty acid and retionol binding protein (Mj-FAR-1) regulates expression of lipid, cell wall, stress and phenylpropanoid-related genes during nematode infection of tomato. BMC Genomics 16:272 https://doi.org/10.1186/s12864-0151426-3.

Ji Y,Chetelat RT (2007) GISH analysis of meiotic chromosome pairing in Solanum lycopersicoidesintrogression lines of cultivated tomato. Genomes 50: 825-833.

Kasal-Slavik T, Eschweiler J, Kleist E, Mumm R, Goldbach HE, Schouten A, and Wildt, J (2017) Early biotic stress detection in tomato (Solanum lycopersicum) by BVOC emissions.Phytochem 144:180-188.

Keller M, Spot in consortium \&Simm S (2018). The coupling of transcriptome and proteome adaptation during development and heat stress response of tomato pollen. BMC Genomics 19(1):447 doi: 10.1186/s12864-0184824-5.

Kil E, Kim S, Lee Y, Byun H, Park J, Seo H, Kim C, Shim J, Lee J, Kim J, Lee, K., Choi, H. and Lee, S. (2016). Tomato yellow leaf curl virus (TYLCV-IL): a seed-transmissible geminivirus in tomatoes. SciRep 6:19013. tps://doi.org/10.1038/srep19013.

Koenig D, Jimenez-Gomez JM, Kimura S, Fulop D, Chitwood DH, Headland L R, Kumar R, Covington MF, Devisetty $\mathrm{UK}$, Tat AV, Tohge $\mathrm{T}$, Bolger A, 
Scheeberger K, Ossowski S, Lanz C, Xiong G, Taylor-Teeples M, Brady SM, Pauly M, Weigel D, Usadel B, Fernie AR, Peng J, Sinha NR and MaloofJN (2013) Comparative transcriptomics reveals pattern of selection in domesticated and wild tomato. ProcNatlAcadSci USA 110 (28), E2655-E2662.

Lovieno P, Punzo P, Guida G, Mistretta C, Van Oosten MJ, Nurcato R, Bostan H, Colantuono C, Costa A, Bagnaresi P, Chiusano ML, Albrizio R, Giorio P, Batelli G\&Grillo S (2016) Transcriptomic changes drive physiological responses to progressive drought stress and rehydration in tomato. Front Plant Sci 7:371.

Lowe R, Shirley N, Bleckley M, Dolan S,Shafee A (2017)PLosComputBiol 13(5):e1005457.

Machado R, Serralheiro RP (2017) Soil salinity: Effect on vegetable crop growth, management practices to prevent and mitigate soil salinization. Horticulturae $3: 30$ doi:10.3390/horticulturae3020030.

Peralta IE, Spooner DM, Knapp S (2005) New species of wild tomatoes (Solanum section Lycopersicum: Solanaceae) from northern Peru. Syst Bot 30(2):424-434.

doi: 10.1600/0363644054223657.

Rahim MA, Jung H, Afrin KS, Lee J,Nou I (2018) Comparative transcriptome analysis provides insights into dwarfism in cherry tomato (Solanum lycopersicum var. cerasiforme). PLoS ONE 13(12): $\mathrm{e} 0208770$ 10.1371/journal.pone.0208770

RazaliR, Bougouffa S, Morton MJL, Lightfoot DJ, Alam I, Essack M, Aroid ST, Kamau AA, Schmockel SM, Pailles Y, Shahid M, Michell CT, Al-Babill S, Ho YS, Tester M, Bajic VB, Sonia N (2018) The genome sequence of the wild tomato Solanum pimpinellifolium provides inshts into salinity tolerance. Front Plant Sci.9(1402) doi: 10.3389/fpls.2018.01402

Rick CM (1990) Perspective from plant genetics: the TomaoGnetics Stock Center. In: McGuire PE,Qualset CO, editors. Genetic resources at risk: scientific issue, technologies and funding policies. Genetic Resources conservation program, University of California 11-20.

Rick C,Tanksley S (1981) Genetic variation in Solanum pennellii: comparison with two other sympatric tomato species. Plant Syst. Evol. 139:11-45.

Sade D, Brotman Y, Eybishtz A, CuadrosInostroza A, Fernie AR, Willmitzer L, (2013) Involvement of the hexose transporter gene LeHT1 and of sugars in resistance of tomato to tomato yellow leaf curl virus. Mol Plant 6:1707-1710.

Sade D, Shriki O, Cuadros-Inostroza A, Tohge T, Semel Y, Haviv Y, Willmitzer L, Fernie A, Czosnek H,Brotman Y (2015) Comparative metabolomics and transcriptomics of plant response to Tomato yellow leaf curl virus infection in resistant and susceptible tomato cultivars. Metabolomics 11(1):81-97. doi: 10.1007/s 11306-014-0670-x.

Sahu, K. K. \&Chattopadhyay, D. (2017).Genome-wide sequence variations between wild and cultivated tomato species revisited by whole genome sequence mapping. BMC Genomics, 18:430.

SarkarD, Maji RK, Dey S,Sarkar A, Gosh Z,Kundu P (2017) Integrated miRNA and mRNA expression profiling reveals the response regulators of a susceptible tomato cultivar to early blight disease. DNA Research 24(3):235250 doi10.1093/dnares/dsx003.

Sato S, Tabata S (2016) Functional Genomics and Biotechnology in Solanaceae and 
Cucurbitaceae Crops. 70doi 10.1007/978-3-662-48535-4_1.

Shukla N, Yadav R, Kaur P, Rasmussen S, Goel S, Agrwal M, Jagnnath A, Gupta R, Kumar A (2018) Transcriptome analysis of root-knot nematode (Meloidogyne incognita)- infected tomato (Solanum lycopersicum) roots reveals complex gene expression profiles and metabolic networks of both host and nematode during susceptible and resistance responses. Mol Plant Pathol 19(3):615-633.

Shwartz I, Levy M, Ori N, Bar M (2016) Hormones intomato leaf development. DevBiol 419(1):132-142

Simmonds Norman (1976). Evolution of crop plants, Longman Group Ltd. ISBN 10: 0582444969.

Tan G, Liu K, Kang J, Xu K, Zhang Y, Hu L, Zhang J, Li C (2015) Transcriptome analysis of the compatible interaction of tomato with Verticillium dahlia using RNA-sequencing. Front Plant Sci6:428438

The 100 Tomato Genome Sequencing Consortium (2014) Exploring genetic variation in the tomato (Solanum section Lycopersicon) clade by wholegenome sequencing. Plant $\mathrm{J}$ 80:136-148.

Tomato Genome Consortium (2012). The tomato genome sequence provides insights into fleshy fruit evolution. Nature 485:635-641.

Van der Beek JG, Verker R,Zabel P,Lindhout P. (1992) Mapping strategy for resistance genes in tomato based on RFLPs between cultivars: Cf9 (resistance to Cladosporiumfulvum) on chromosome 1. TheorAppl Genet 84:12.

Wang Y, Tao X, Tang XM, Xiao L, Sun JL, Yan XF, Li D, Deng HY, Ma XR (2013) Comparative transcriptome analysis of tomato (Solanum lycopersicum) in response to exogenous abscisic acid. BMC Genomics 14:841.

Wang Z, Gerstein M, Snyder M (2009) RNASeq: a revolutionary tool for transcriptomics. Nat Rev Genet (PMC).

Ye J, Hu T, Yang C, Li H, Yang M, Ijaz R, Ye Z, Zang Y (2015) Transcriptome Profiling of Tomato Fruit Development Reveals Transcription Factors Associated with Ascorbic Acid, Carotenoid and Flavonoid Biosynthesis. PLoS ONE 10(7): e0130885. doi:10.1371/journal.pone.0130885

Zhan Y, Qu Y, Zhu L, Shen C, Feng X, Yu C (2018) Transcriptome analysis of tomato (Solanum lycopersicum L.) shoots reveals a crosstalk between auxin and stringolactone. PLoS ONE 13(7:e0201124).

\section{How to cite this article:}

Kinjal Kulshrestha and Akarsh Parihar. 2020. A Decade of Tomato Transcriptomics: Status and Perspectives. Int.J.Curr.Microbiol.App.Sci. 9(03): 2026-2056. doi: https://doi.org/10.20546/ijcmas.2020.903.235 